\title{
El renacimiento de una sala de cine de los años 1920 : el cinema Louxor en París ${ }^{1}$
}

\author{
Philippe Pumain \\ Traductores: Andrés Ávila Gómez y Diana Carolina Ruiz
}

1. El presente texto, fue escrito originalmente en francés por el arquitecto Philippe Pumain, quien dirigió en todas sus etapas (durante casi cinco años) el proyecto de rehabilitación del cinema Louxor, el cual reabrió sus puertas en la primavera de 2013. Este texto fue publicado en : Le Louxor. Palais du cinéma, Bruxelles: AAM Éditions, 2013, p. 112

145. Traducción realizada por: Andrés Ávila Gómez y Diana Carolina Ruiz.

2. Philippe Pumain, arquitecto director del proyecto ; Fabre/Speller, arquitectos asociados ; Christian Laporte, arquitecto de patrimonio ; BMI, agencia de estudios estructurales ; Louis Choulet, especialistas en instalaciones ; AVA, especialistas en acústica ; DAL, economía de la construcción ; Scène, especialistas en escenografía ; Cartel collections, asesoría en restauración de pinturas.

3. El Forum des Images -situado en el corazón del sector de Halles-, institución adscrita a la Mission Cinéma, realizó el seguimiento permanente a todos los aspectos relacionados con la cinematografía.
El 7 de noviembre de 2007, el equipo que habíamos constituido ${ }^{2}$ para participar en la convocatoria de proyectos para la renovación del cinema Louxor, penetraba por primera vez en el interior de esta antigua sala de cine situada al norte de París, descubriendo espacios y muros que lucian aun los decorados de la discoteca Megatown que había funcionado allí antes de su cierre hace poco más de dos décadas.

Casi seis meses después de aquella primera visita con nuestro equipo, y luego de un proceso de selección que recibió propuestas de 65 equipos de profesionales, recibí un correo con fecha 19 de mayo de 2008, remitido por la Direction du Patrimoine et de l'Architecture en el cual se me informaba que la Commission d'appel d'offres de la Ville de Paris había emitido un concepto favorable que atribuía a nuestro equipo el proyecto de rehabilitación del cinema Louxor, lo cual sería confirmado oficialmente por el Conseil de Paris en la sesión del 26 de mayo de 2008. La notificación oficial del contrato fue comunicada el 17 de junio de 2008, dando así inicio a nuestra misión para rehabilitar el Louxor, con el objetivo de abrir el edificio al público en el primer semestre de 2013.

La convocatoria de proyectos en la cual participamos seguía los lineamientos de un dossier de consultation muy detallado que incluía además de los habituales documentos contractuales, una serie de documentos generales (extracto del Plan Local d'Urbanisme, Schéma Directeur d'Accessibilité de la Ville de Paris, Charte du Patrimoine et de l'Architecture, entre otros); un levantamiento topográfico actualizado; los diagnósticos reglamentarios de niveles de plomo y asbesto; documentos técnicos (estudio de suelos, concepto dictado por la Inspection Générale des Carrières, diagnóstico estructural del edificio, esquemas acústicos, etc.); y una tríada de documentos realizados entre 2005 y 2007, fundamentales para guiar nuestra reflexión : el proyecto cultural, el programa funcional, y el estudio de factibilidad, todos ellos elaborados bajo la tutela de la oficina de estudios Coteba y traducidos bajo la forma de un programa arquitectónico y técnico. Incluía igualmente el estudio histórico y patrimonial realizado en 2005 por los arquitectos Arnaud de Pémille y Frédéric Martorello, ampliado con una investigación que realizó la empresa Quélin sobre los decorados que el edificio exhibió en épocas pasadas, junto con un análisis de materiales realizado por la sociedad LEM Laboratoires.

Al interior del gobierno municipal de la Ville de Paris, la Mission Cinéma, un organismo adscrito directamente al Secrétariat général de la Ville, asumió la supervisión del proyecto: este organismo tenía entre sus principales misiones, la realización de actividades tan variadas como apoyar la producción de cortometrajes; organizar una serie de festivales anuales dedicados al séptimo arte (entre ellos "Paris Cinéma "); la promoción del cine en las instituciones educativas escolares; y el seguimiento y control de alrededor de 800 rodajes anuales de películas cinematográficas rodadas total o parcialmente en Pa-ris ${ }^{3}$. Sin embargo, dado que la Mission Cinéma no poseía una estructura que garantizara plenamente la supervisión operativa de un proyecto arquitectónico de esta magnitud, dicha labor fue delegada

* Cómo citar esta traducción: Pumain, P. (2018). El renacimiento de una sala de cine de los años 1920: el cinema Louxor en París. Trad. por A. Ávila-Gómez y D. C. Ruiz. Apuntes, 31(1), 116-149. https://doi.org/10.11144/ 


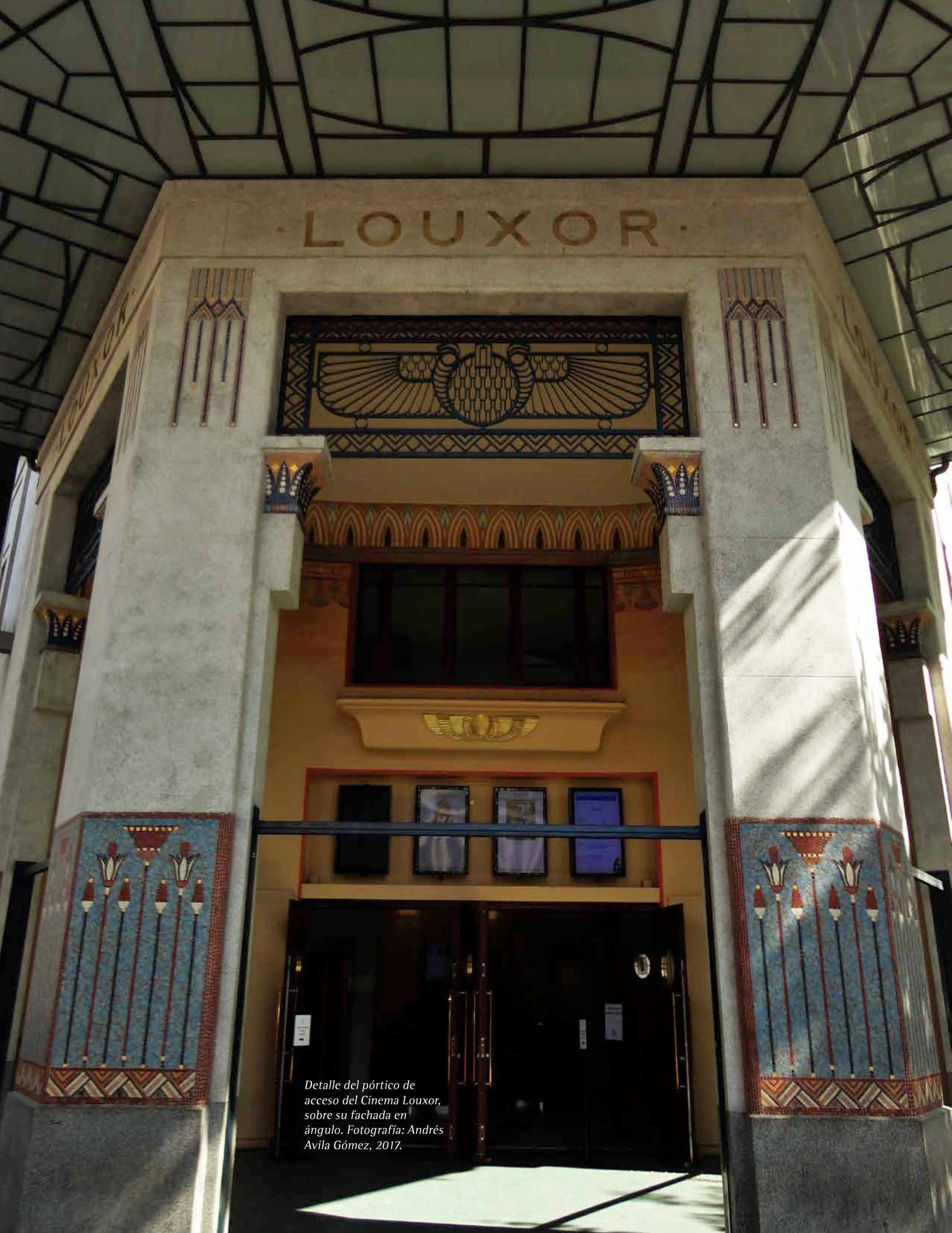




\section{El renacimiento de una sala de cine de los años 1920 : el cinema Louxor en París}

Philippe Pumain

philippe@pumain.fr

http://pumain.fr/

Architecte D.P.L.G : ENSA Paris-La Villette.

Entre sus proyectos realizados más importantes en el ámbito de la arquitectura para el espectáculo, se destacan: la modernización del Théâtre du Rond-Point (París, 2009, con Fabre/Speller); Sala de conciertos del Mariinsky Theatre (San Petersburgo, 2006, con Fabre/Speller); reestructuración del Grand Théâtre de la Maison Internationale (París, 2004, con Fabre/Speller). Actualmente : Rehabilitación del Théâtre du Châtelet (París, desde 2017, con C. Laporte).

Traductores

Andrés Ávila Gómez

ORCID: http://orcid.org/0000-0003-3883-2737

andresavigom@gmail.com

Investigador asociado del HiCSA - Histoire culturelle et sociale de l'art : Université Paris 1 Panthéon-Sorbonne. Docto-

Traducción rando en Histoire de l'art : Université Paris I Panthéon-Sorbonne. Magister en Ville, architecture, patrimoine : Université Paris 7 Diderot. Magister en Urbanismo : Universidad Nacional de Colombia (Bogotá). Arquitecto : Universidad de Los Andes (Bogotá). http://univ-paris1.academia.edu/AndresAvila

Diana Carolina Ruiz

ORCID: http://orcid.org/0000-0001-5524-0456

karorr2002@gmail.com

Profesional en Langues Etrangères Appliquées: Université Paris IV Paris-Sorbonne

Master (en curso) en Etudes Hispaniques et Hispano-américaines: Université Paris IV Paris-Sorbonne 

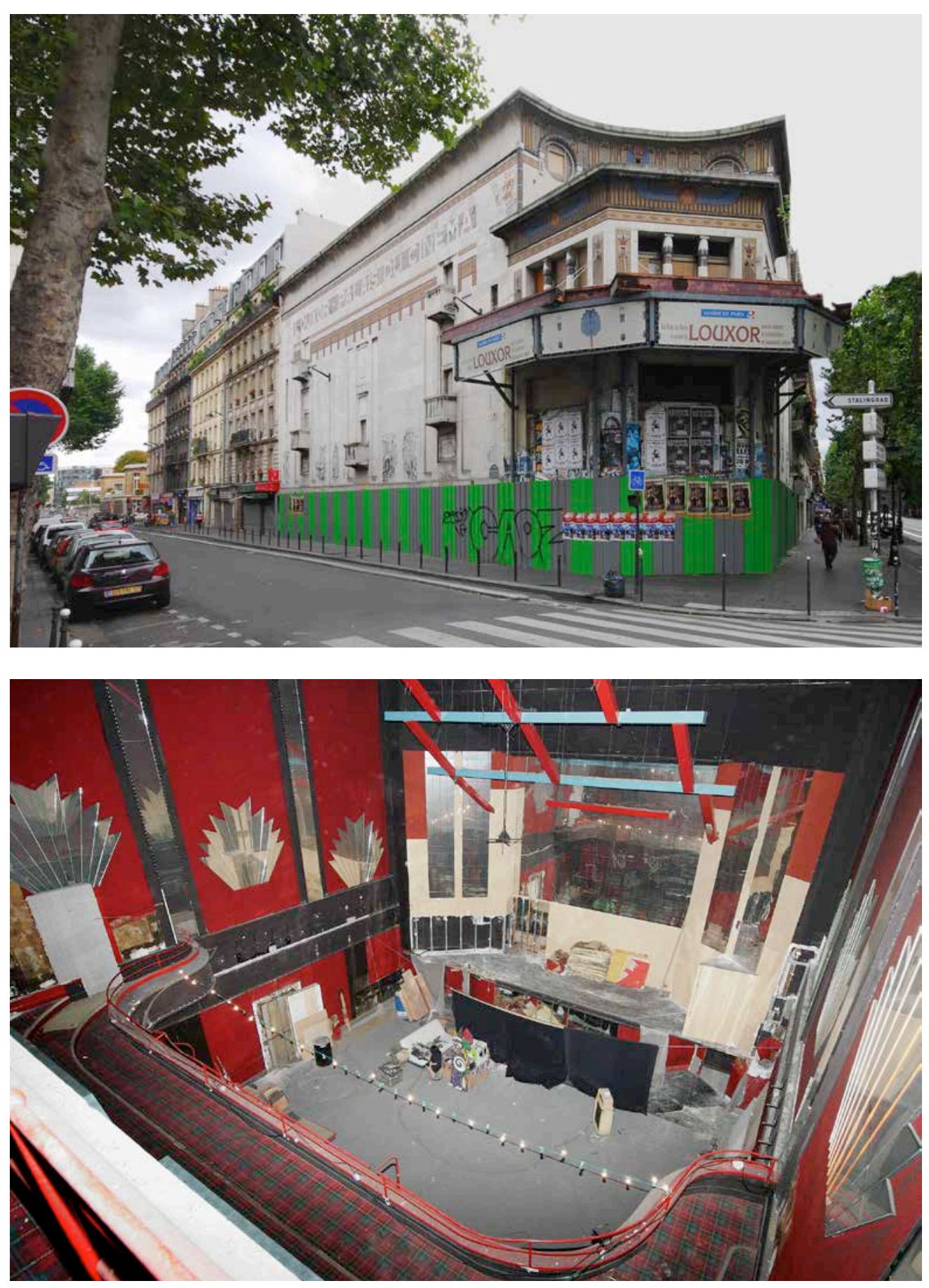

especialmente a la Agence des Grands Projets -convertida en 2010 en la Agence de Conduite de Projets- de la Direction du Patrimoine et de l'Architecture de la Ville de Paris.

El programa general establecido en la convocatoria correspondía al de un equipamiento localizado en un sector urbano en mutación, destinado esencialmente a la exhibición cinematográfica y clasificado como sala "d'Art et d'Essai" cuya rehabilitación debería responder a tres objetivos claros : reequilibrar la oferta de exhibición cinematográfica en el sector occidental de París -caracterizado por el déficit de estos equipamientos-; asegurar la diversidad en la oferta cinematográfica de la capital francesa; y convertirla en una verdadera "sala de cine de proximidad" que por su dimensión y su programación constituyera una poderosa herramienta de animación cultural para el barrio y el distrito que la albergan. El programa estaba estructurado en torno a tres salas para la proyección cinematográfica, cada una de diferente capacidad: la más grande con aproxi-
Figura 1.

Estado de las fachadas del Louxor en 2007

(Fotografía: Art

Graphique et Patrimoine)

Figura 2.

Restos de la decoración de la discoteca

Megatown, en 2007 (Fotografía: Pascal Dhennequin) 
Figura 3.

Restos de la decoración de Megatown en el primer sótano (Fotografía: Pascal Dhennequin)

4. La definición del programa fue objeto de diversos y complejos estudios (de mercado, etc.) realizados por solicitud del gobierno de la Ville de Paris, con lo cual se dio forma al programa incluido en el pliego de la convocatoria.

5. Para los proyectos de rehabilitación de edificios existentes, el gobierno de la Ville de Paris, fijó un nivel máximo de consumo anual de $80 \mathrm{kWh}$ ep. $/ \mathrm{m}^{2}$ SHON. Vale la pena señalar que antes de la intervención actual, el consumo anual del Louxor había sido calculado en aproximadamente 540 kWh ep./m² SHON, es decir, casi siete veces la cifra actual esperada.

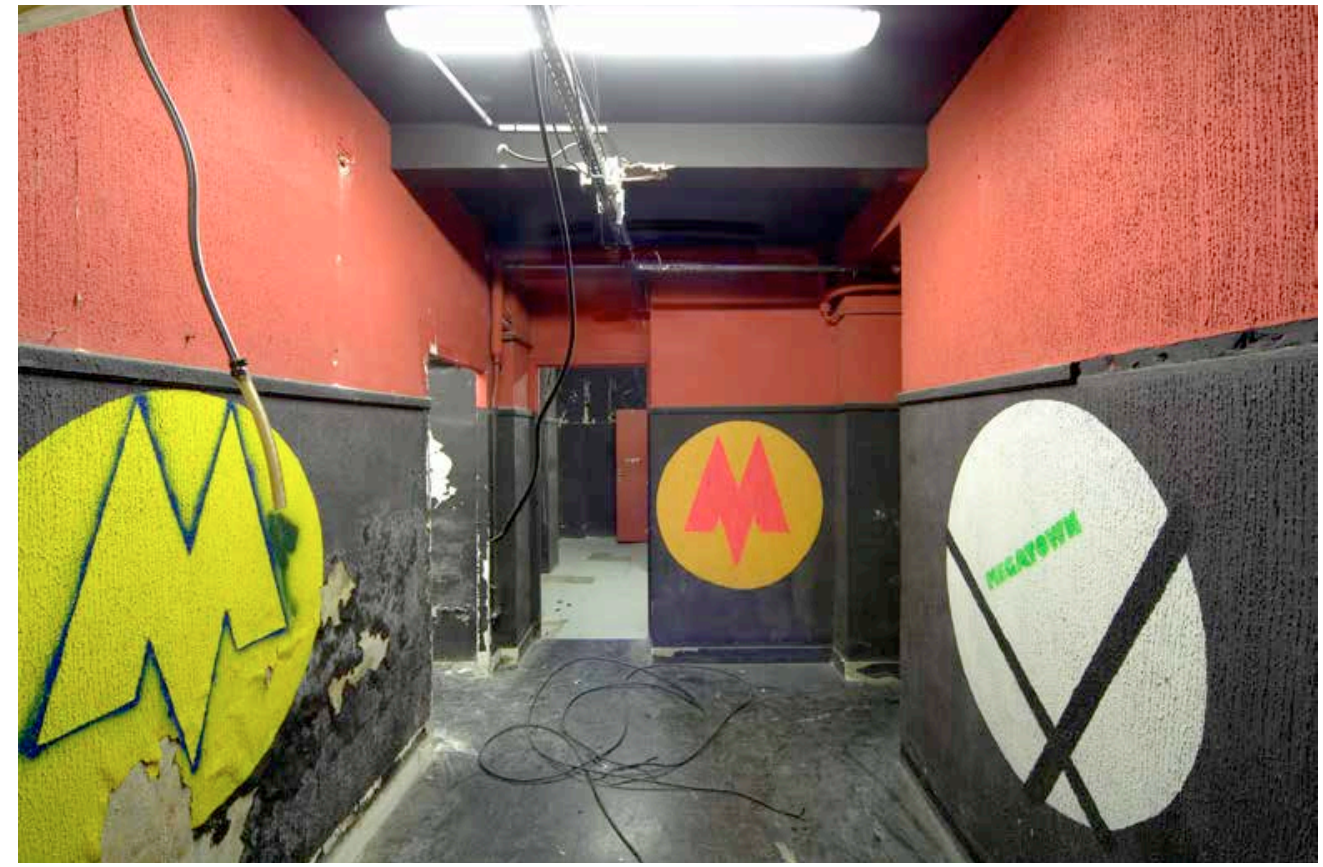

madamente 300 plazas, la mediana con 150 y la pequeña con 80 plazas $^{4}$, planteando en el caso de la sala mediana la posibilidad de albergar espectáculos animados-especialmente musicales-. El programa debía completarse con un café-club de $60 \mathrm{~m}^{2}$, una sala de exposición de $30 \mathrm{~m}^{2}$, tres oficinas para la administración, y todos los espacios anexos y técnicos necesarios para el correcto funcionamiento de un equipamiento de este tipo.

Las exigencias programáticas y las diversas restricciones identificadas en el pliego de condiciones del proyecto, e ilustradas en el estudio de factibilidad dejaban entrever tras la aparente simplicidad del proyecto, una extraordinaria complejidad paradójicamente acentuada por el tamaño relativamente modesto del predio: aproximadamente $580 \mathrm{~m}^{2}$. Tales exigencias y restricciones estaban asociadas fundamentalmente a la estratégica posición urbana del edificio en el corazón del sector Barbès; a la elevada calidad ambiental demandada en torno a tres elementos principales (economía de la energía consumida de acuerdo al Plan Climat de la Ville de Paris ${ }^{5}$; control de mantenimiento y de las performances futuras del equipamiento; confort acústico); y por último, al profundo valor simbólico y patrimonial del edificio. En tal sentido, es importante señalar que las fachadas y los techos habían sido inscritos casi tres décadas atrás en el Inventaire Supplémentaire des Monuments Historiques [Inventario Suplementario de Monumentos Históricos], por medio del decreto del 5 de octubre de 1981; y por otro lado, lado, que el estudio patrimonial previo a los trabajos de renovación mostraron que subsistian algunos decorados interiores que databan de la construcción original de 1921. En 2007, el presupuesto asignado para la ejecución del proyecto -incluyendo los equipos cinematográficos- fue de un total de 13,3 millones de euros.

\section{Los principales objetivos del proyecto de renovación}

\section{Un equipamiento implantado en el corazón del barrio y de la ciudad}

El Louxor está situado en el cruce de dos ejes importantes: el eje norte-sur formado por los boulevards Magenta y Barbès, y el eje occidenteoriente formado por los boulevards Rochechouart y La Chapelle, a lo cual se suma tanto su notoria visibilidad desde el tramo elevado de la línea $n^{\circ} 2$ del metro de París, como desde las vías de circulación aledañas. Llamado a desempeñar gracias a su carácter patrimonial un rol fundamental en la revalorización del sector de Barbès, el proyecto de rehabilitación del Louxor se enfocó esencialmente en la puesta en práctica de un principio de restauración completa de las fachadas fiel al estado inicial de su aspecto en 1921, devolviendo la integralidad del decorado egiptizante -incluyendo las astas inspiradas en aquellas de los pilones de templos egipcios y que habían desaparecido en los años 1940, para ser usadas en la señalización 


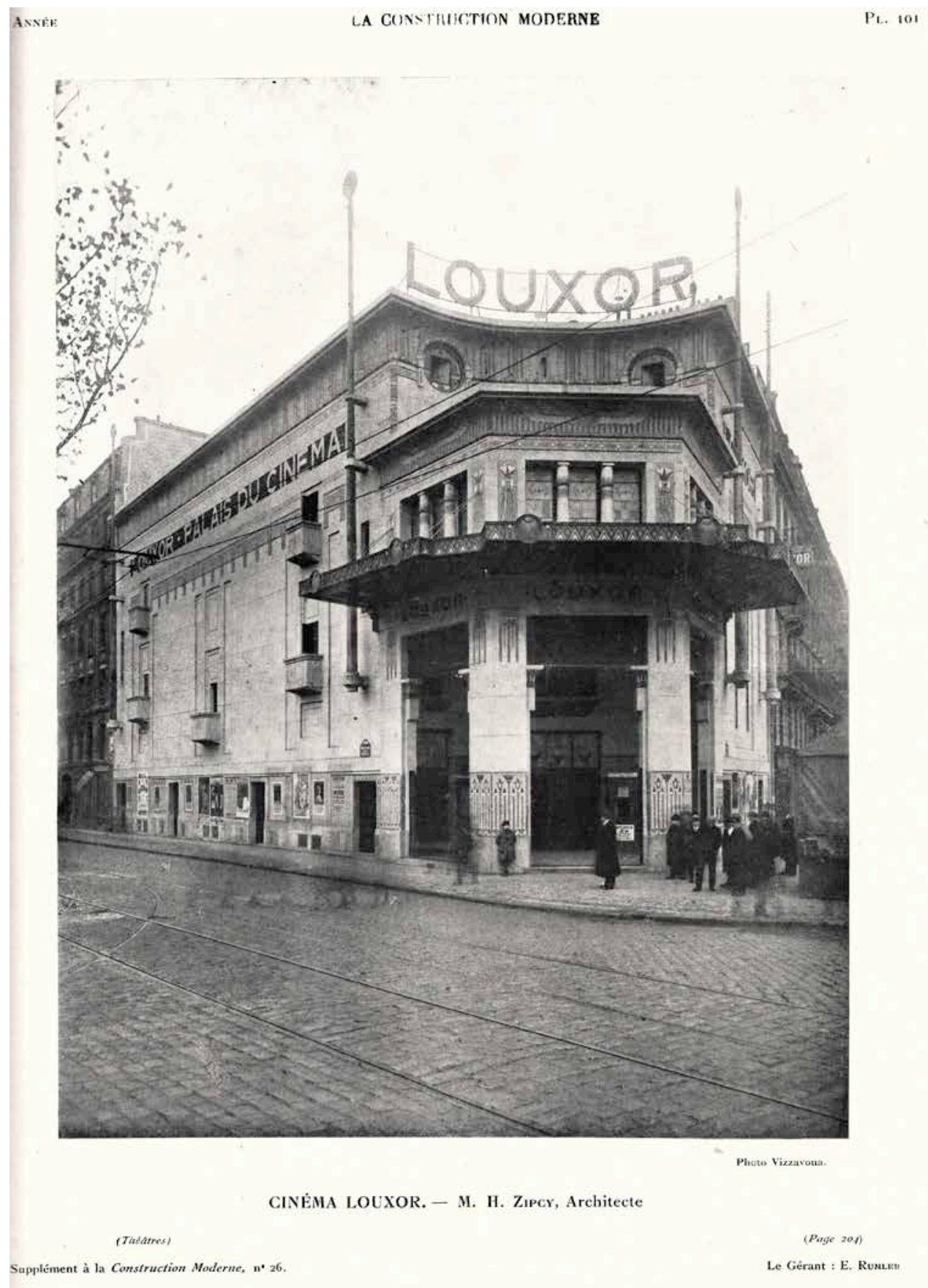

del cinema, particularmente en la noche gracias al uso de discos luminosos-.

La proposición de una reapertura total del pórtico, tal y como había funcionado originalmente, resultaba coherente con dicho principio: devolviendo dicho espacio a la ciudad se incitaría a los transeúntes a acudir al edificio para observar las funciones cinematográficas y las diversas actividades propuestas: exposiciones, animaciones, bar, etc..... El pórtico permitiría igualmente controlar la totalidad o al menos gran parte de la fila de espera para las taquillas sin invadir los andenes, y estaría cerrado por rejas articuladas que serían usadas solamente durante las horas de cierre del equipamiento.

\section{Un carácter patrimonial fortalecido}

Además de las exigencias derivadas de la inscripción en el lnventaire Supplémentaire des Monuments Historiques, como en el caso del cinema Louxor -en esta ocasión la protección aplicaba únicamente a la envolvente del edificio-, nuestro equipo se interesó por recuperar en el proyecto
Figura 4.

Vista exterior del Louxor poco después de su inauguración en 1921. (Fuente: La Construction Moderne, 26 de marzo de 1922, lámina 101) 
de rehabilitación la relación entre el decorado egiptizante de las fachadas y el decorado interior -particularmente en la gran sala-, tal y como había existido en el proyecto original de Henri Zipcy. Dicha relación desapareció por completo en el transcurso de los años 1930 cuando se cambió abruptamente la temática decorativa de la sala para adoptar un estilo neogriego, abriendo asi el camino para la adopción de una sucesión de estilos heterogéneos y cada vez más banales, especialmente entre los años 1950 y los años 1980.

Con este nuevo proyecto de rehabilitación, se buscaba recuperar el carácter monumental del edificio y su fuerza de expresión en el espacio público, a través de trabajos tendientes a restituir los mosaicos eliminados desde hace muchos años, y a regenerar los recubrimientos en granito. Globalmente, los trabajos planteados para intervenir la envolvente del edificio correspondían a tres órdenes : la restitución de antiguas intenciones arquitectónicas (como por ejemplo: el hundimiento de la fachada sobre el boulevard de Magenta, la restitución de las astas, la reapertura del pórtico hacia el exterior); la restauración de elementos en concreto y mortero de recubrimiento sobre los paramentos; y la regeneración de las epidermis compuestas por mosaicos tanto en granito como en cemento.
En cuanto a los mosaicos, elementos fundamentales de las fachadas, se hicieron necesarios dos tipos de trabajos : la restauración de los mosaicos existentes, y por otro lado, la restitución -previa elaboración en un taller externo- de los desparecidos mosaicos particularmente de aquellos que formaban la cornisa más elevada ubicada en el costado del boulevard de La Chapelle.

Es importante precisar que las fotografías más antiguas muestran como hasta los años 1940, algunos vitrales decoraban tanto los vanos del foyer/sala de exposiciones ubicado en la tercera planta, como también los óculos sobre la fachada en ángulo del cinema. Aunque el diseño de los paneles de vitrales podía ser restituido teniendo en cuenta la información derivada de la iconografía disponible sobre las características del edificio durante los años 1920 y 1930, el hecho de que todas las imágenes de la época sean en blanco y negro hizo necesario restituir los elementos de color buscando la coherencia con la policromía de los mosaicos que enmarcan los vitrales, inspirándose para ello en ejemplos históricos contemporáneos a la construcción del Louxor. Durante los trabajos de rehabilitación del edificio, la Association des Amis du Louxor descubrió una carta postal de la época que revelaba que los dos grandes vanos verticales que componen la fachada sobre el

Figura 5.

Interior de la gran sala en 2007, vista hacia los balcones (Fotografía: Pascal Dhennequin)

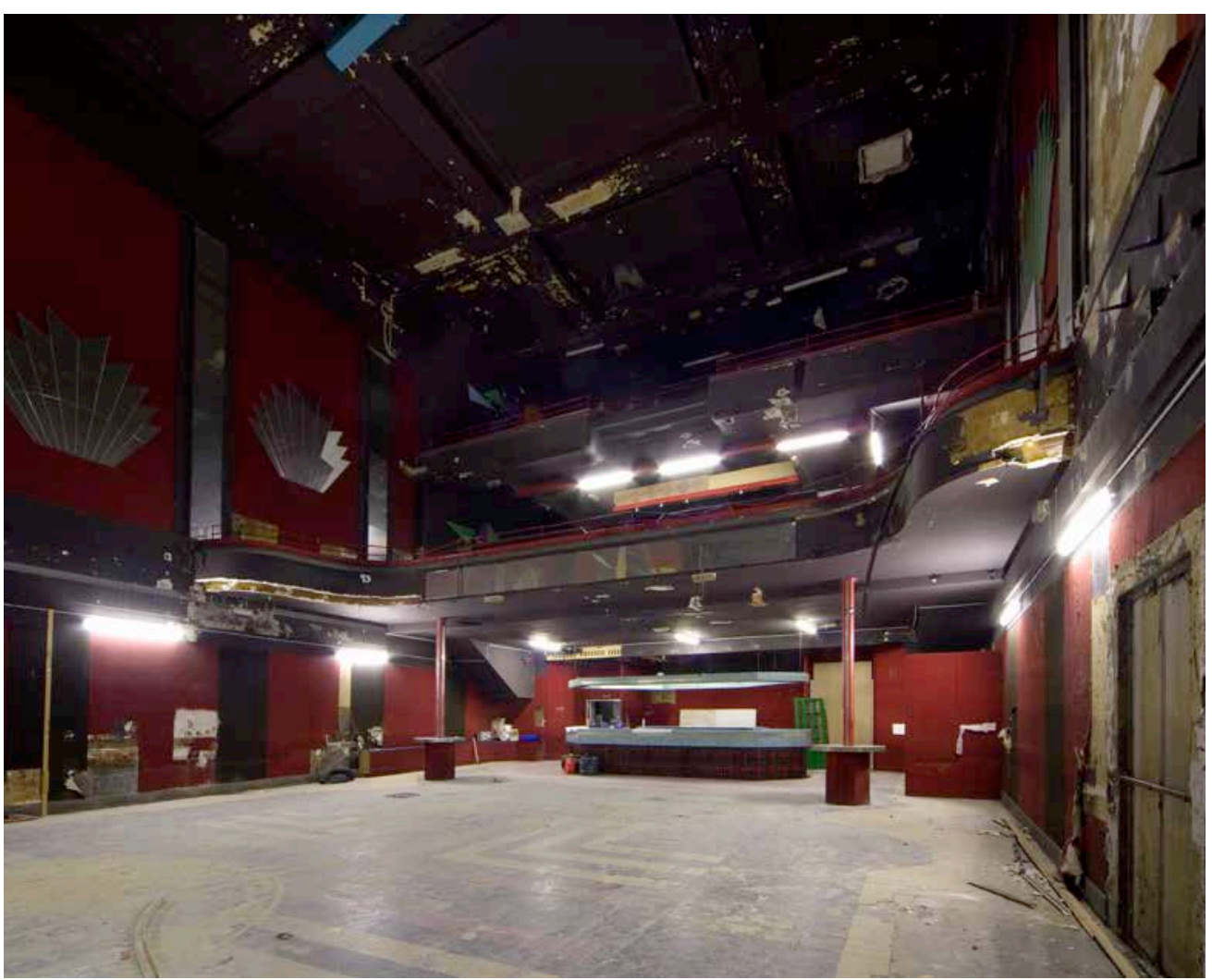


boulevard de Magenta tuvieron también vitrales, ante lo cual se decidio restituirlos tras la debida concertación y aprobación por parte de la Direction Régionale des Affaires Culturelles.

En lo que respecta a la señalización empleada en el Louxor, se consideró que debido a su decoración excepcional que incluye las inscripciones incorporadas en sus fachadas, no era necesario ni deseable añadir elementos adicionales ${ }^{6}$ asegurando así la puesta en valor de sus excepcionales fachadas; y se propuso también rescatar las vitrinas de presentación laterales -con iluminación incorporada- para ofrecer una alternativa adicional para anunciar la programación cinematográfica exhibida en el Louxor.

\section{Un equilibrio complejo}

Dos principios orientaron la forma en la cual se abordó el diseño interior: la voluntad de respetar de la manera más fiel posible la composición arquitectónica original del edificio -incluyendo claro está, la excepcional volumetría de la gran sala-; y el deseo ya evocado de recuperar tanto en el exterior como en el interior del Louxor la coherencia entre el lenguaje arquitectónico y el

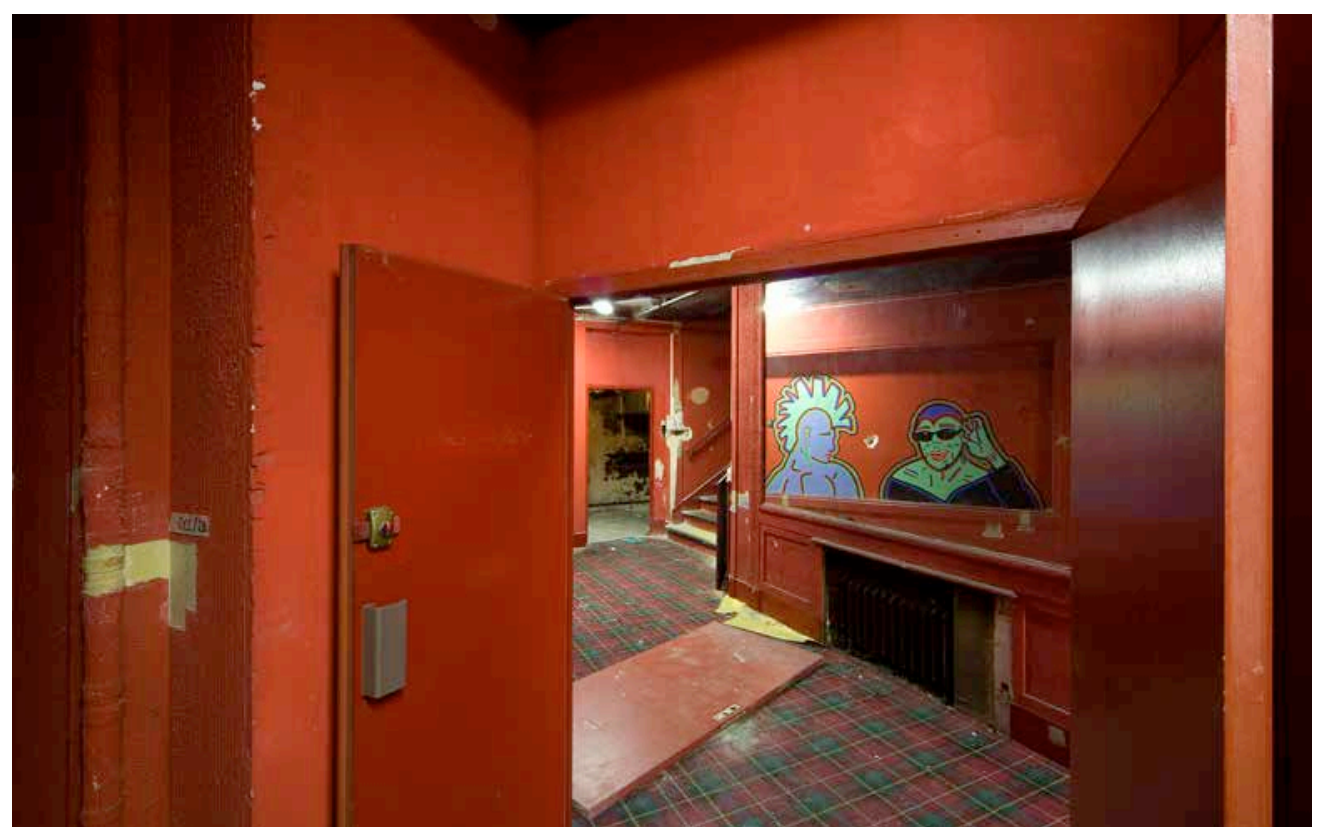

6. Es importante señalar que, desde el año siguiente a su inauguración, el Louxor estuvo decorado con numerosos avisos publicitarios luminosos, pero se consideró finalmente que no era deseable restituir tales elementos por cuanto no hicieron parte del diseño original del arquitecto del Louxor, y chocarían sin duda hoy en día con la calidad patrimonial del edificio.

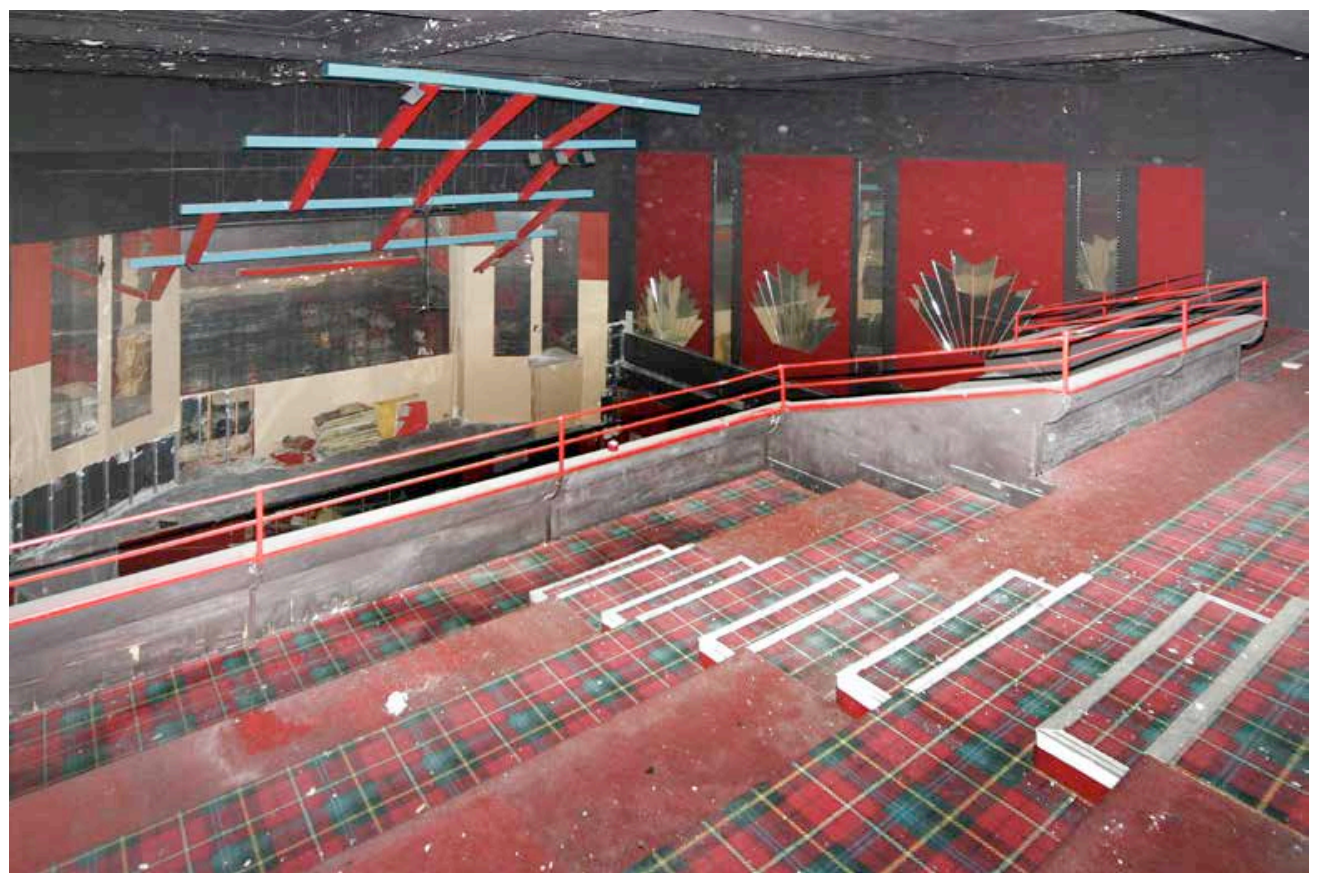

Figura 6.

Restos de la decoración de la discoteca

Megatown, en una de las salidas del segundo piso (Fotografía: Pascal Dhennequin)

Figura 7.

Restos de la decoración de la discoteca Megatown, desde el segundo balcón (Fotografía: Pascal Dhennequin) 
decorativo. Estos dos principios nos condujeron por un lado, a implantar en el sótano las dos nuevas salas requeridas en el programa, dejando de lado la idea de dividir el volumen de la gran sala original; y por otro lado, a restituir fielmente la decoración egiptizante de la gran sala, antes que a considerar un nuevo decorado ex nihilo.

\section{Exigencias acústicas}

La reapertura del Louxor como sala de cine requería la implementación de un " cubo al interior de otro cubo " capaz de funcionar de forma independiente con respecto a las estructuras existentes del propio edificio como también de los inmuebles vecinos. Por tal motivo, los elementos del decorado original que data de 1921 que aún estaban presentes en muros y techo de la gran sala -ocultos bajo capas de decorados ulteriores-, debieron ser cubiertos luego de haber servido como modelos de referencia y de haber sido reproducidos en los nuevos muros de la sala.

Se adoptó entonces el principio según el cual las tres salas de cine podían ser concebidas como cubos o cajas aisladas entre ellas. Con el fin de responder a esta exigencia, las placas inferiores de las dos nuevas salas que se encuentran en el sótano están formadas por losas flotantes que reposan sobre una solera de hormigón, soportando las superestructuras del edificio. Por otro lado, el " cubo al interior de otro cubo " que corresponde a la gran sala, está conformado por una placa inferior en hormigón que es soportada por vigas metálicas instaladas sobre cajas de muelles. Una serie de pórticos metálicos rellenos en mampostería constituye los muros de la caja en cuestión, coronada por un techo en placas de yeso sobre las cuales descansa un colchón de aislamiento que forma la sexta cara del cubo acústico. Los pórticos soportan igualmente los dos balcones de la sala, reconstruidos en estructura metálica, con lo cual ellos mismos funcionan aislados de las estructuras existentes.

\section{Exigencias estructurales}

Se identificaron varias problemáticas estructurales que requerían soluciones técnicas específicas, comenzando por el subsuelo constituido por antiguas canteras rellenadas. La pésima calidad del suelo y el empuje de la tierra constatado al momento de construir las dos salas localizadas en el subsuelo exigieron la implementación adicional de trabajos de cimentación sobre una serie de pozos en concreto armado asentados en micropilotes perforados a casi veinte metros de profundidad.

La inercia de los muros laterales del edificio fue reforzada gracias al uso de grandes pórticos metálicos que aportaron a la rigidez de los elementos existentes en concreto armado, equilibrando así el sostenimiento de la envolvente del edificio. Con el fin de respetar el aislamiento acústico, dichos pórticos fueron tratados de forma independiente a la estructura principal.

Por otra parte, la carga soportada por las dos vigas Vierendeel en concreto armado que soportan la parte central de la cubierta, fue alivianada gracias a los pórticos de arrostramiento creados para tal fin, y a las vigas y placas existentes conservadas en el proyecto de rehabilitación, reforzados a su vez con perfiles metálicos o con plats en carbono según el caso.

\section{Integración de los equipos técnicos}

El principio general aplicado para la ventilación de las tres salas y de los principales espacios consistió en utilizar centrales de tratamiento de aire repartidas en varios puntos del edificio, para lo cual el precalentamiento del aire se realiza por medio de una bomba de calor implantada en el volumen del edículo situado entre las dos vigas Vierendeel. Alimentada por una captación de la capa freática situada a casi 80 metros de profundidad, la bomba -apta para producir simultáneamente calor y frio- asegura también el enfriamiento del edificio. Se utilizó una instalación geotérmica provista de una bomba de calor al nivel de la capa freática para así respetar las disposiciones del Plan Climat de la Ville de Paris (consumo inferior a $80 \mathrm{kWh}$ ep./m² SHON/año)

\section{Exigencias de seguridad y de accesibilidad}

Con el propósito de responder a las normas de seguridad y de accesibilidad fueron creadas nuevas escaleras como complemento de la escalera histórica -a su vez conservada y restaurada-, y se dispuso también un ascensor exclusivo para personas de movilidad reducida que facilita su acceso a todos los niveles del edificio. Además, en aplicación del estatuto que rige en París, sobre la accesibilidad para todos, las tres salas de cine y 
los principales espacios públicos del edificio (hall, foyer/sala de exposición, bar) fueron equipados con bucles de inducción de audiofrecuencia que permiten a las personas con discapacidad auditiva recibir directamente en sus aparatos auditivos la señal de audio del film proyectado. Igualmente, cada una de las tres salas de cine dispone de un dispositivo de audio-descripción de los films, destinado a las personas con discapacidad visual o con ceguera.

\section{Implantación de los dispositivos cinematográficos}

Las salas están equipadas con proyectores digitales, y en el caso de la gran sala y de la mediana, estas cuentan adicionalmente con proyectores de $35 \mathrm{~mm}$ para así responder a la programación d'Art et d'Essai, permitiendo la proyección de patrimonio cinematográfico que en buena parte no se encuentra aún digitalizada -y que quizás no llegue a serlo jamás-. La cabina de proyección de la gran sala -bautizada Youssef Chahine- está situada en el lugar de la antigua cabina, mientras que las otras dos salas comparten una cabina común localizada en la parte inferior del sótano.

La pantalla de la gran sala es retráctil, permitiendo regularmente la realización de proyecciones sobre una pantalla de formato menor -pintada directamente sobre el muro tal y como sucedía con el dispositivo original instalado en 1921-, y dejando además que los espectadores contemplen eventualmente la integralidad del decorado original restituido.

\section{La evolución del proyecto durante las fases de estudio}

Desde el momento de nuestra designación, nuestro equipo inicio una serie de rigurosas y detalladas visitas de estudio al Louxor ${ }^{7}$, lo cual nos permitió profundizar los estudios para complementar los diagnósticos previos, basándonos en un conocimiento cada vez más preciso de lo existente y enriquecido con una serie de importantes descubrimientos fortuitos.

\section{Los estudios de anteproyecto}

Basándonos en los principios definidos en el pliego de la convocatoria, definimos inicialmente un anteproyecto básico entre junio y septiem- bre de 2008, y un anteproyecto definitivo entre octubre de 2008 y enero de 2009. Para validar las hipótesis referentes a la restitución desde un punto de vista patrimonial, completamos el estudio histórico reconstituyendo con precisión los planos y los cortes del Louxor según el estado original del edificio al momento de su apertura en 1921: este ejercicio nos permitió entender que las disposiciones presentes en la licencia de construcción otorgada en 1920 no fueron respetadas al pie de la letra al momento de realizar la obra.

Tanto por el añadido de cinco pequeños balcones en la fachada que da sobre el boulevard de La Chapelle -para responder seguramente con tres de ellos a ciertas exigencias de accesibilidad de servicios de socorro, mientras que los otros dos cumplían con una función estrictamente decorativa por efectos de simetría-, como por la modificación de la volumetría de la sala, la bóveda prevista en el diseño original fue reemplazada por un techo artesonado con dos vigas Vierendeel longitudinales.

Por otro lado, no fue posible confirmar si en algún momento el Louxor contó con las 1.370 plazas anunciadas en la época de la apertura de la sala, aunque según los estudios resultaba evidente que desde el momento mismo de su inauguración se llevaron a cabo modificaciones importantes en este aspecto : cotejando los escasos documentos fotográficos de la época con los vestigios existentes, se dedujo que la capacidad máxima que tuvo el Louxor fue de aproximadamente 1.140 plazas, de las cuales 1.020 eran sillas y 120 correspondían a asientos plegables. Los estudios adelantados durante las fases del anteproyecto sirvieron esencialmente para aclarar información necesaria relacionada con el diseño original. Con base en ello se redefinió la capacidad de las tres nuevas salas: inicialmente programadas con una capacidad de aproximadamente 300, 150 y 80 plazas, se optó finalmente por ajustarlas para albergar 342, 140 y 74 plazas. El café-club, bautizado "Bar du Louxor», que inicialmente se había planeado acondicionar en el tercer piso, se ubicó finalmente en el cuarto piso permitiéndole disponer de una conveniente y agradable superficie adicional para su uso.

En la misma línea de lo hecho durante el proceso de concertación que previamente se había dado entre el gobierno de la Ville de Paris con
7. Durante nuestras primeras visitas y hasta el momento en que se iniciaron los trabajos previos de desamiantización, nos encontramos en el Louxor en repetidas ocasiones a un simpático ocupante que en aquel momento tenía un ambiguo contrato de arrendamiento de una parte del edificio : se trataba de Abadi, un baterista del grupo Pow Wow, de Emilie Simon y más tarde de Amadou et Mariam, quien había implantado desde hacía años su estudio de ensayo en el sótano del Louxor, el cual había podido conservar incluso después de la compra del predio por parte de la alcaldía de la ciudad de París, por cuanto se entendió que su presencia permanente allí contribuía enormemente a reducir los riesgos de una invasión y ocupación de la propiedad, clausurada dos décadas atrás. 


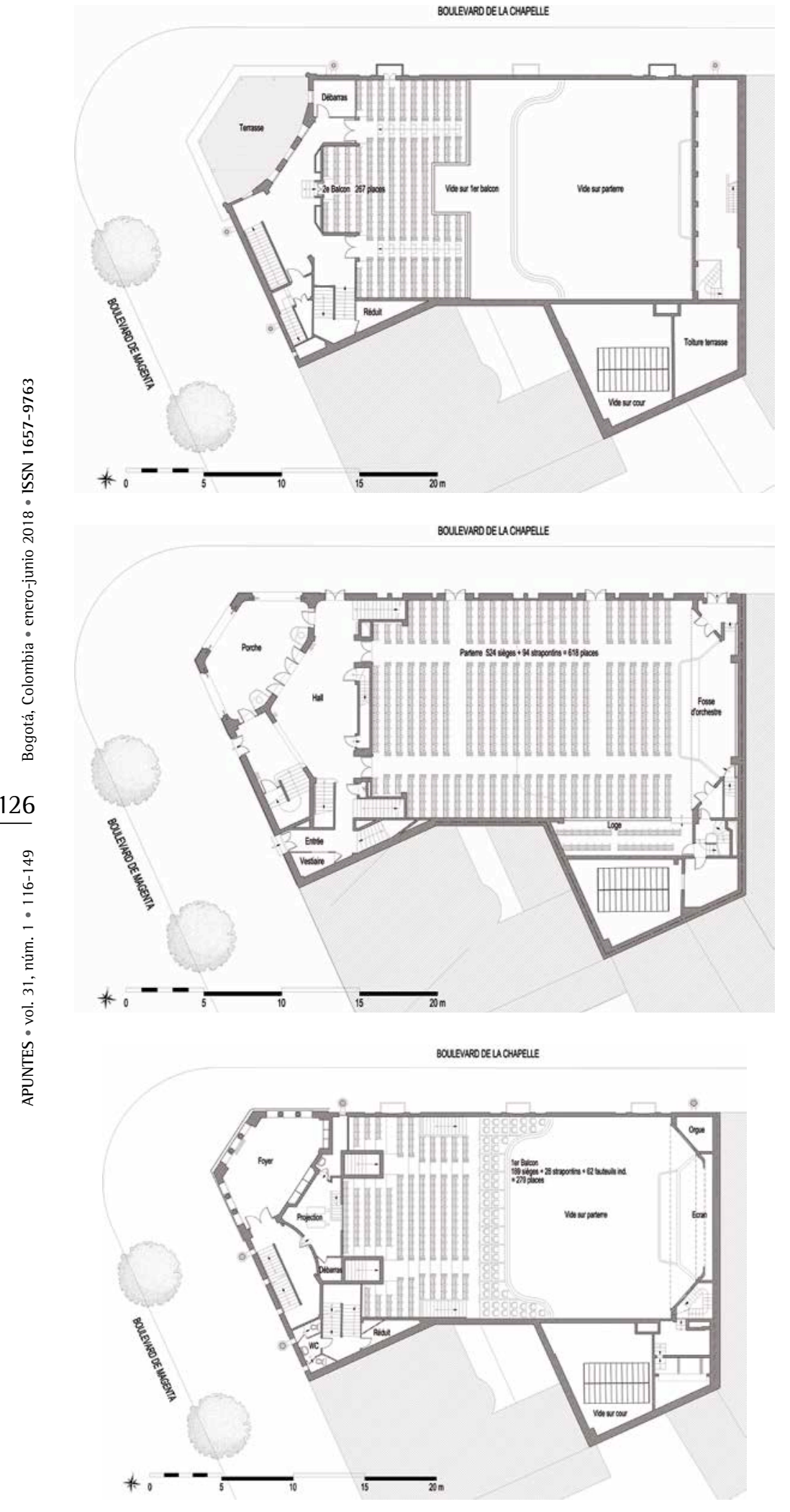

Figuras 8, 9 y 10. Planos de hipótesis de restitución del aspecto original de la gran sala en 1921 : segundo balcón (arriba), platea (en el medio), y primer balcón (abajo). (Fuente: Arquitectos del proyecto)

los habitantes del sector y con las asociaciones locales, organizamos múltiples presentaciones del proyecto en el marco de concurridas reuniones públicas, principalmente con ocasión de la producción de los expedientes del anteproyecto y de la licencia de construcción. Dada la relevancia del Louxor, tanto en su territorio administrativo que corresponde al distrito 10, como para los vecinos distritos 9 y 18, dichas presentaciones públicas del proyecto -en sus diferentes etapas- dieron lugar a enriquecedores debates que se enfocaban menos en cuestiones formales del proyecto, priorizando en cambio la discusión en torno a la diversidad del programa arquitectónico definido originalmente y en las posibles implicaciones de este en las decisiones arquitectónicas y técnicas -como sucedió por ejemplo, con la solución del " cubo al interior de otro cubo "-. La participación en tales debates, así como el valioso trabajo de comunicación y de pedagogía a propósito de la rehabilitación largamente esperada del Louxor por todo un sector de la ciudad de París, nos permitió enriquecer y fortalecer in fine nuestro proyecto.

\section{La licencia de construcción}

La solicitud de la licencia de construcción fue realizada en marzo de 2009 sobre la base del anteproyecto definitivo validado por el cliente. Paralelamente, una solicitud de autorización comercial para la explotación del futuro establecimiento consagrado a la exhibición cinematográfica fue presentada ante la Commission Départementale d'Aménagement Commercial, que otorgó su respuesta positiva en abril de 2009.

El trámite de la licencia de construcción -proceso siempre demorado en París-, para un establecimiento abierto al público - y protegido parcialmente en este caso por su inscripción en el Inventaire Supplémentaire des Monuments Historiques- que debe responder satisfactoriamente a normas muy precisas de seguridad y de accesibilidad, se retardó más de lo esperado debido a que desde principios del año 2009 el sector Barbès fue clasificado como zona " sensible ". Igualmente, el proyecto fue objeto de una investigación de seguridad y de protección del público llevada a cabo por la Préfecture de Police, ante lo cual la licencia de construcción fue concedida finalmente el 8 de enero de 2010.

\section{Los dossiers de convocatorias}

Durante el tiempo en que se radicó la licencia de construcción, entre marzo y junio de 2009, se elaboraron los correspondientes estudios de 

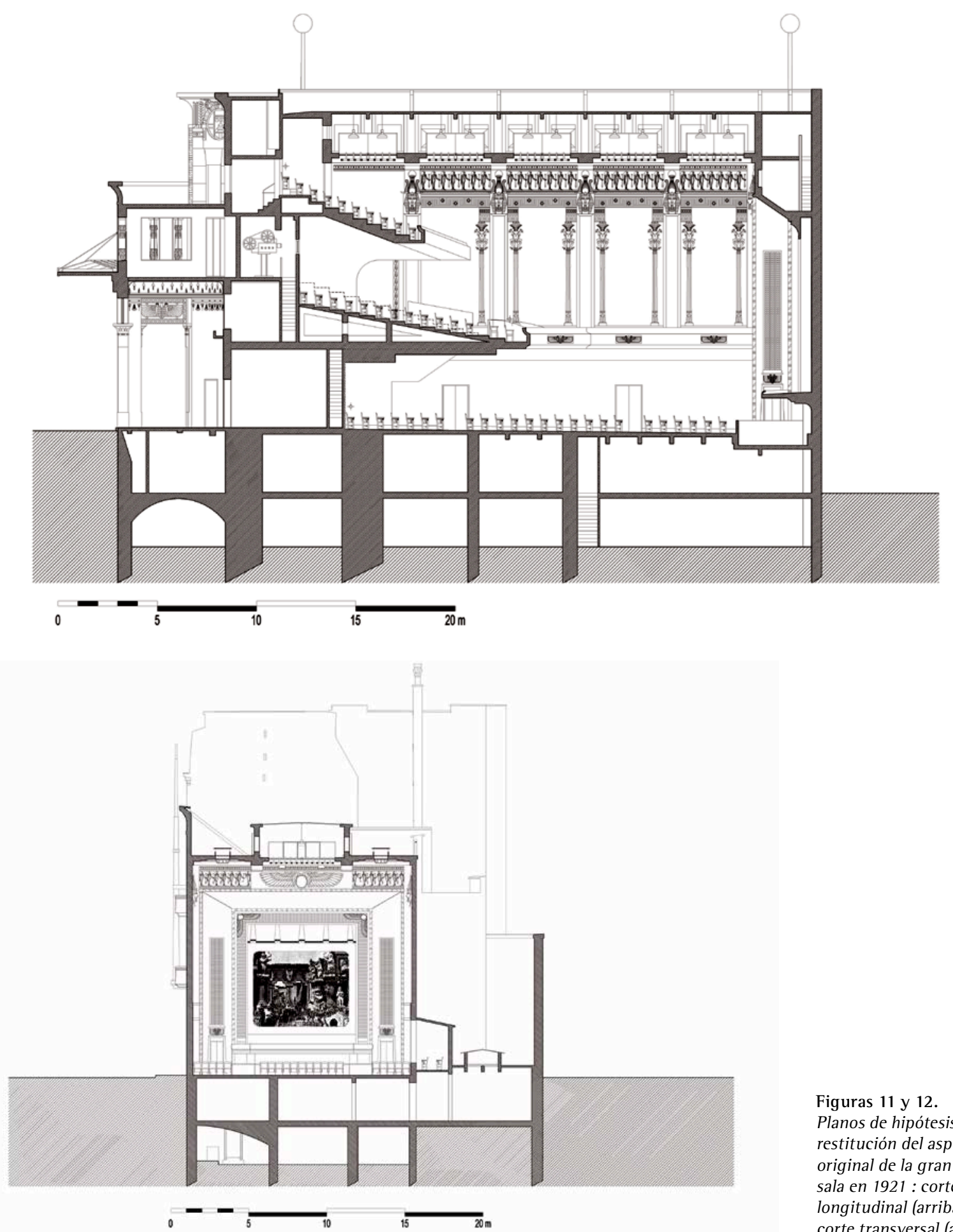

proyecto, es decir, la elaboración de los planos arquitectónicos y técnicos, y los detalles y descripciones de los trabajos que al ser validados por el cliente, sirvieron de base para los dossiers de las convocatorias abiertas para seleccionar las firmas que ejecutarían dichos trabajos bajo la coordinación de nuestro equipo. Se prestó especial importancia por ejemplo, a temas como las sillas de la gran sala, con el propósito de encontrar un diseño similar al original, del cual algunos coleccionistas
Figuras 11 y 12 .

Planos de hipótesis de restitución del aspecto original de la gran sala en 1921 : corte longitudinal (arriba), $y$ corte transversal (abajo). (Fuente: Arquitectos del proyecto) 


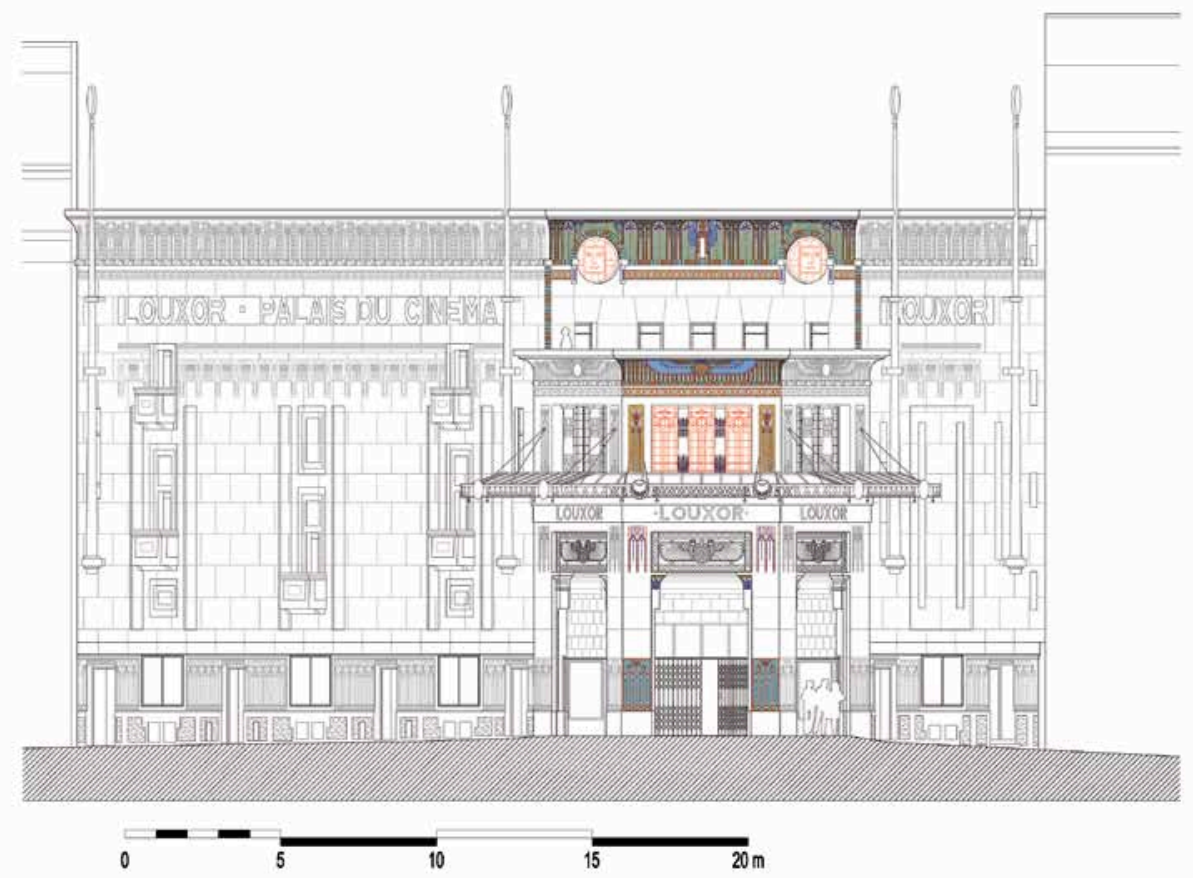

Figuras 13 y 14 . Representación de la fachada del Louxor vista desde el angulo nor-occidental (arriba), y sobre el boulevard de Magenta (abajo). (Fuente: Arquitectos del proyecto)

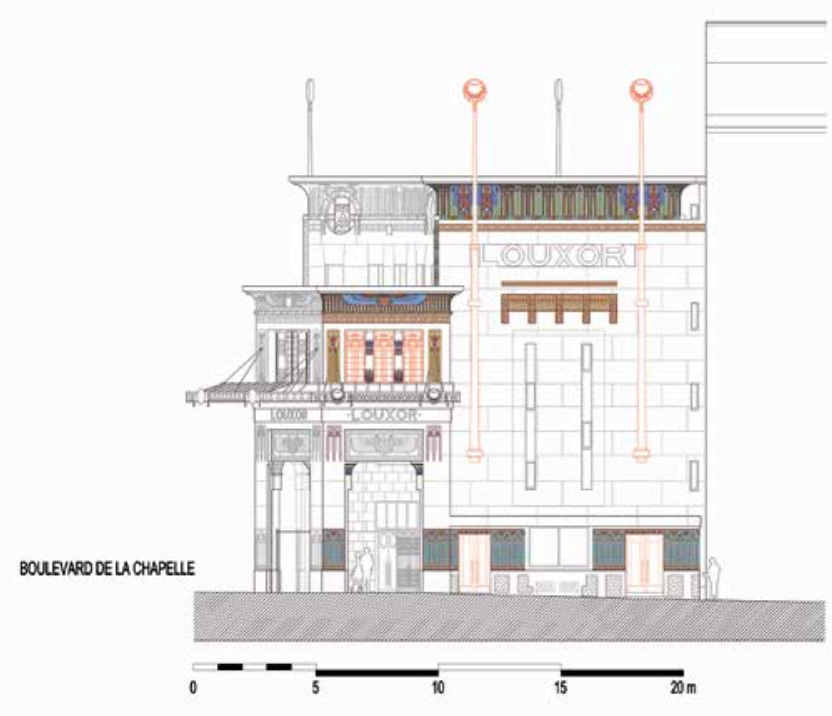

e instituciones conservaban algunos ejemplares, particularmente la Cinémathèque Française.

Así, debido a la especificidad del proyecto y en especial al carácter patrimonial del mismo, se identificaron diecinueve áreas para las cuales se formularon convocatorias a nivel europeo, entre ellas : la restauración de fachadas, la restauración de decorados -mosaicos, vitrales, etc.-, los trabajos de calefacción-ventilación-plomería, los trabajos eléctricos, la silletería de las salas, los equipos cinematográficos, etc. La convocatoria pública fue lanzada a finales de septiembre de 2009, y las pro- 

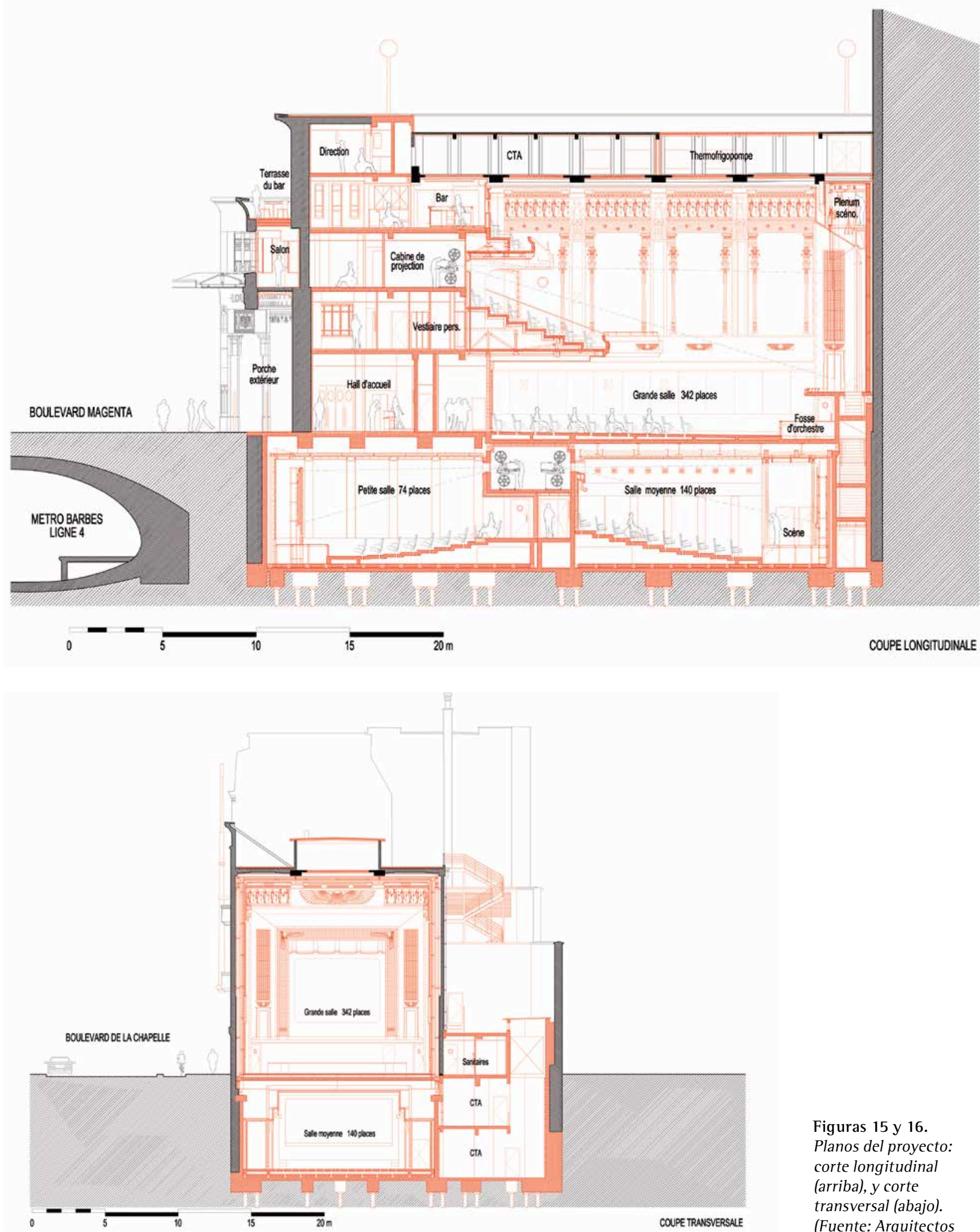

Figuras 15 y 16. Planos del proyecto: corte longitudinal (arriba), y corte transversal (abajo). (Fuente: Arquitectos del proyecto)

puestas fueron recibidas hasta finales de noviembre del mismo año, con lo cual se procedió a evaluarlas, y se contrató la mayor parte de los trabajos con las empresas seleccionadas en junio de 2010.
Los trabajos previos

Cuatro campañas de intervención fueron programadas para ser ejecutadas antes del inicio de la obra 


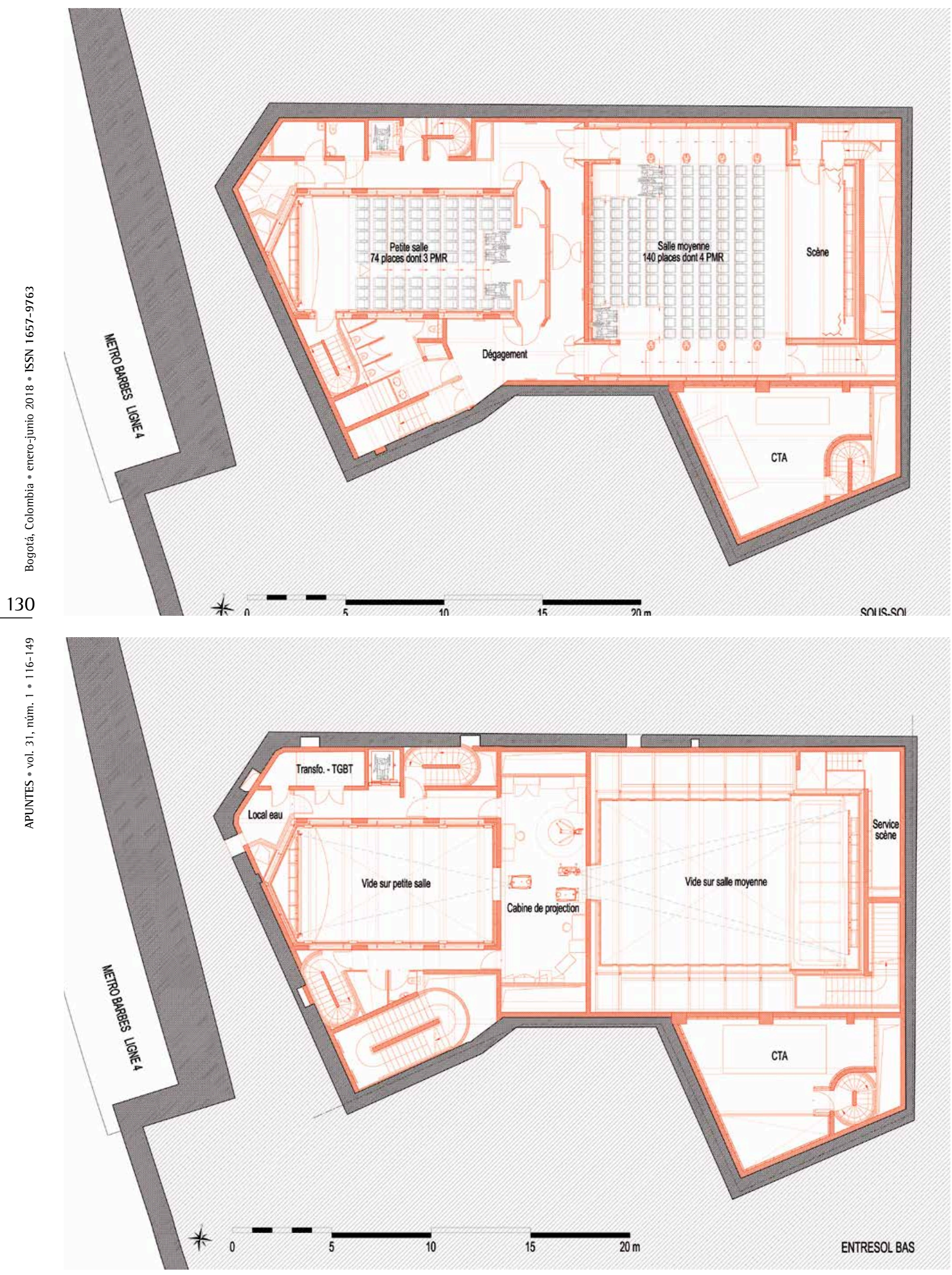




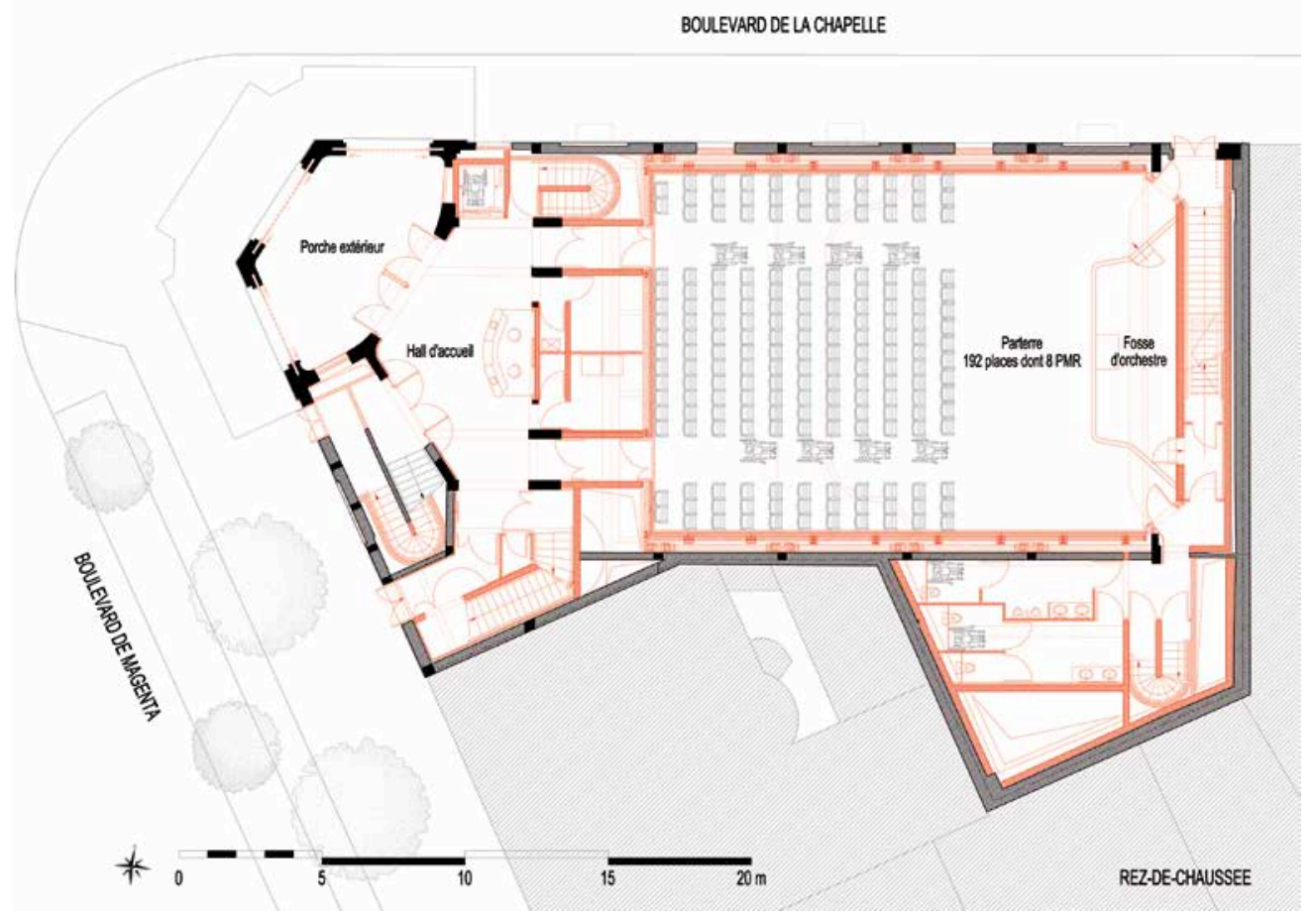

principal, con el objetivo de confirmar algunas de las hipótesis plasmadas en el pliego inicial, y de no perturbar el desarrollo y programación de la obra principal. Estas cuatro campañas fueron respectivamente: la limpieza, la desasbestización, los trabajos patrimoniales, y la perforación hidrogeológica.
Figuras 17 y 18 (página anterior). Planos del proyecto: segundo sótano (arriba), y primer sótano (abajo).

Figuras 19 y 20 (en esta página). Planos del proyecto: primer piso (arriba), $y$ segundo piso (abajo). (Fuente: Arquitectos del proyecto)

\section{BOULEVARD DE LA CHAPELLE}

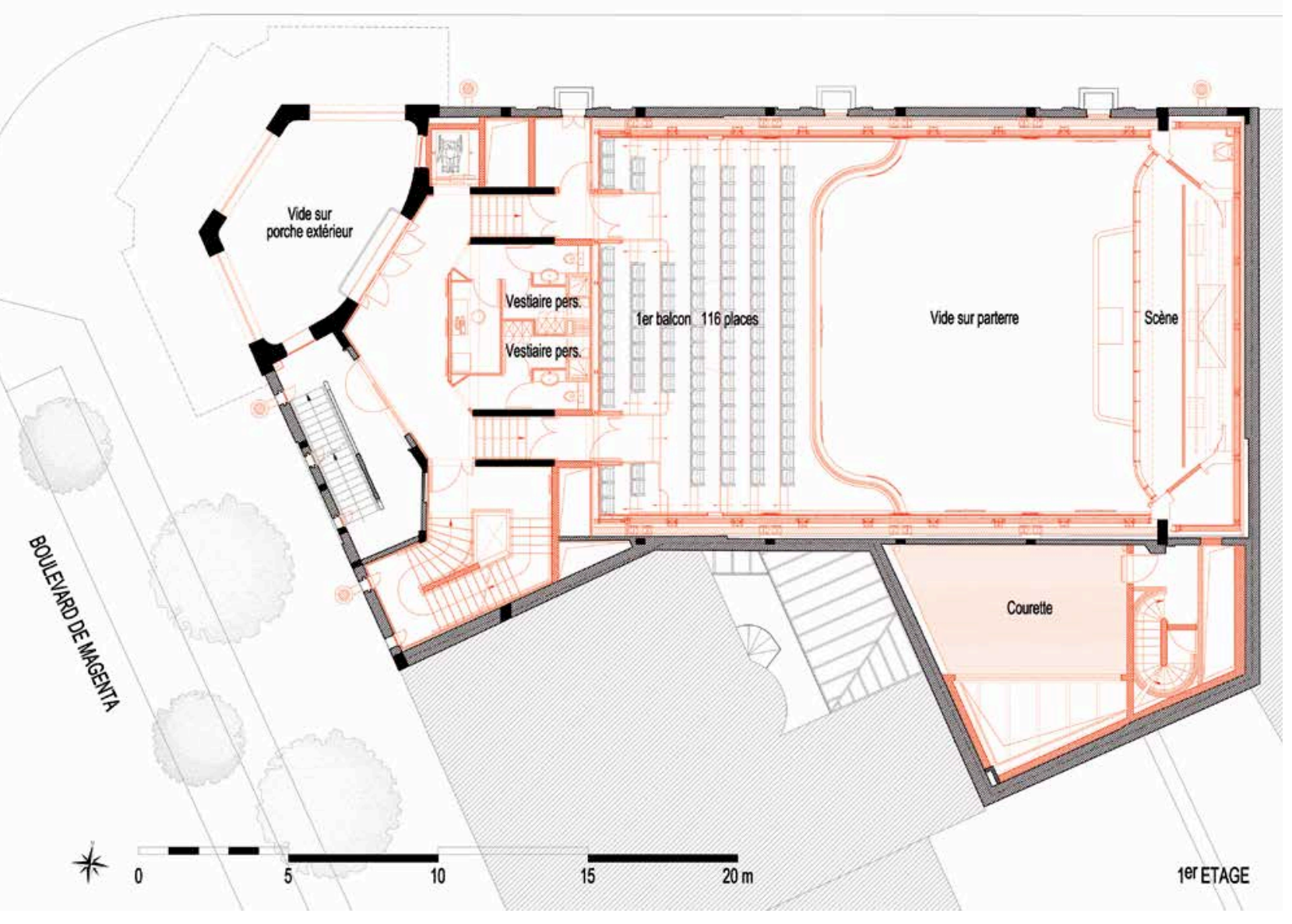




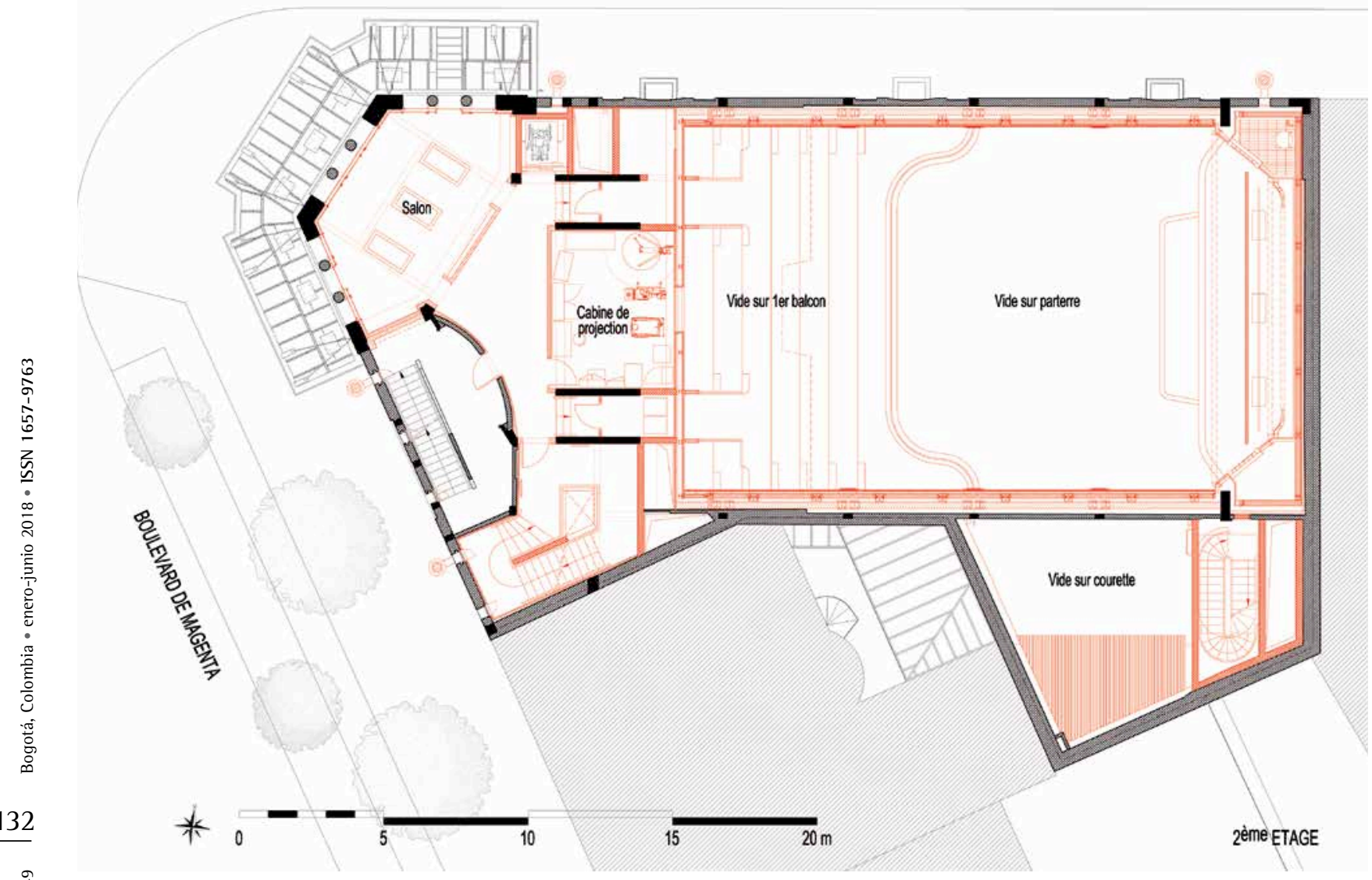

Figuras 21 y 22. Planos del proyecto: tercer piso (arriba), y cuarto piso (abajo).

(Fuente: Arquitectos del proyecto)

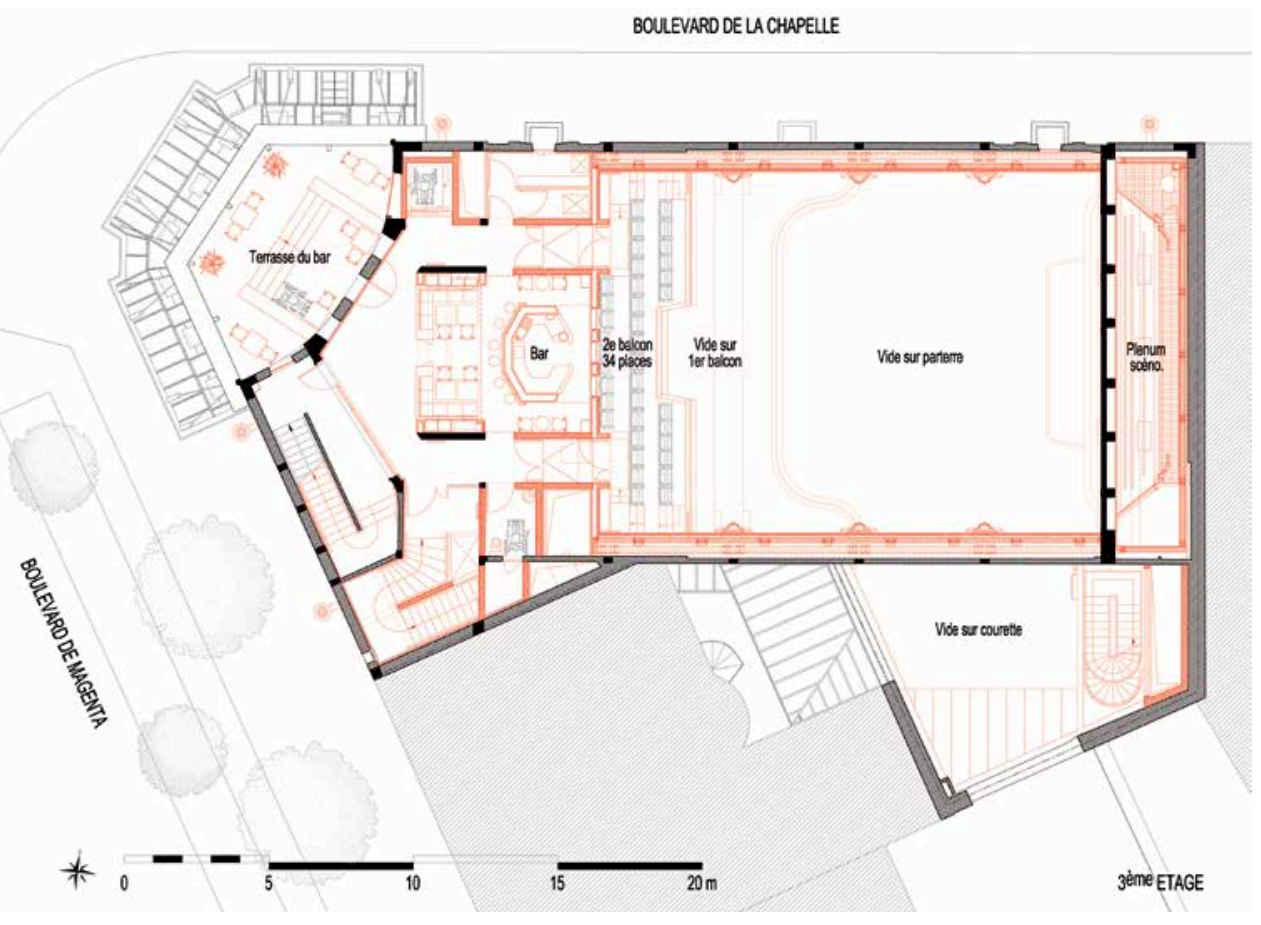

\section{La limpieza}

8. La campaña de limpieza fue realizada por la firma Claisse Bâtiment.
Como resultado de una licitación específica, se llevó a cabo entre los meses de junio y julio de
2009 una campaña de limpieza ${ }^{8}$ de los elementos no estructurales. En esta etapa se retiraron los espejos y de los revestimientos en alfombra instalados sobre los muros de la gran sala, lo cual 


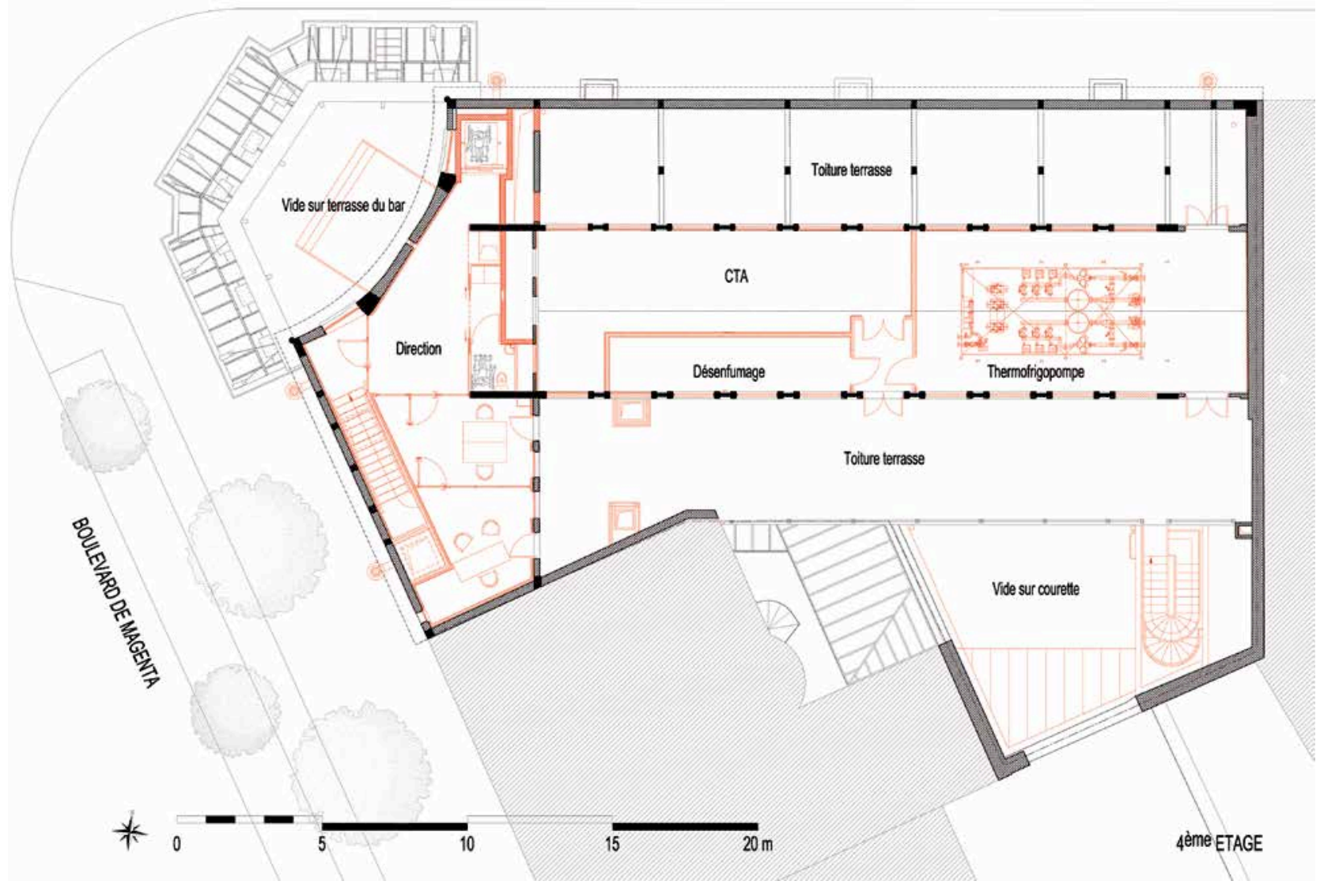

permitió identificar plenamente el decorado original de los años 1930 realizado con motivo de la transformación de la sala original para la exhibición de cine sonoro y de la compra del Louxor por parte de la firma Pathé: se trata de un decorado de estilo neogriego que reemplazó entonces el decorado original neoegipcio.

\section{La desasbestización}

Debido a la concepción estructural del edificio, esencialmente en hormigón armado, el Louxor se encontraba casi libre de la presencia de asbesto, y sin embargo, se decidió realizar una rápida campaña de desasbestizacion ${ }^{9}$ para retirar los restos del material utilizado entre los años 1960 y 1980 especialmente en pegamentos para revestimientos de pisos y en algunos ductos a base de fibrocemento. La eliminación de dichos materiales potencialmente peligrosos fue realizada inmediatamente después de la campaña de limpieza -entre julio y agosto de 2009-, cumpliendo con todas las condiciones de seguridad exigidas por la norma.
Los trabajos patrimoniales

Entre noviembre de 2009 y abril de 2010, dando continuidad a las investigaciones históricas realizadas anteriormente y como condición previa a los trabajos de rehabilitación definitivos del edificio, se realizaron algunos trabajos patrimoniale ${ }^{10} \mathrm{du}$ rante los cuales de despejó un tramo destinado a servir como modelo para la restitución del decorado interior de la gran sala. Dicha intervención constituyó la ocasión para consolidar y proteger los decorados aun conservados en algunos muros, antes de implantar la caja acústica proyectada. En las zonas de recepción (el pórtico, la antigua escalera, etc...), los elementos del decorado original que fueron descubiertos bajo las capas añadidas en posteriores intervenciones fueron consolidados y protegidos para su posterior restauración.

\section{La perforación hidrogeológica}

Con el fin de validar la aplicación de geotermia en lo concerniente a la calefacción y al enfriamiento del edificio, se realizó una perforación profunda
Figura 23.

Plano del proyecto: quinto piso.

(Fuente: Arquitectos del proyecto)
9. La desasbestización fue realizada por la firma SBDR.

10. Los trabajos patrimoniales fueron realizados por la firma Eschlimann. 


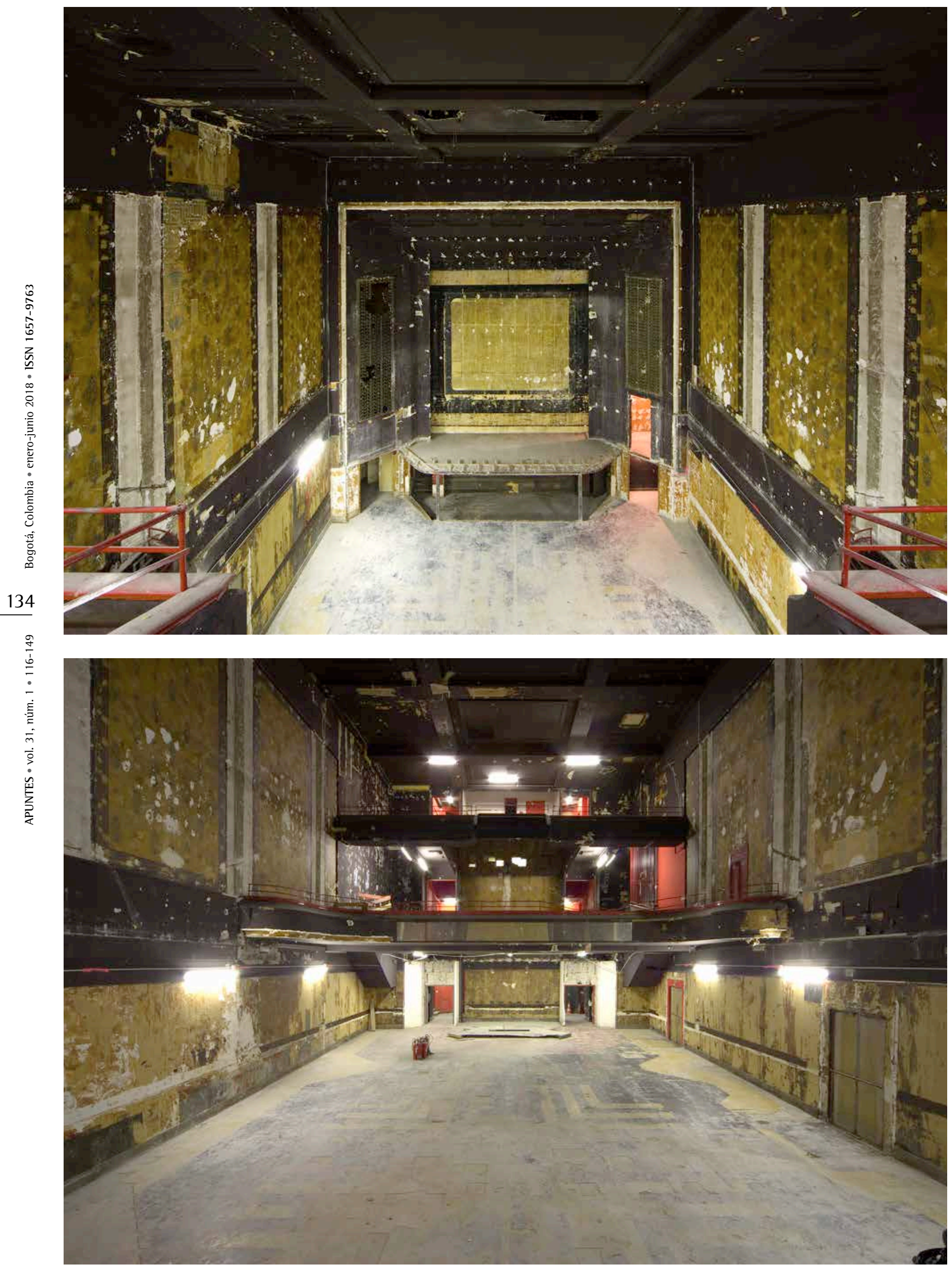




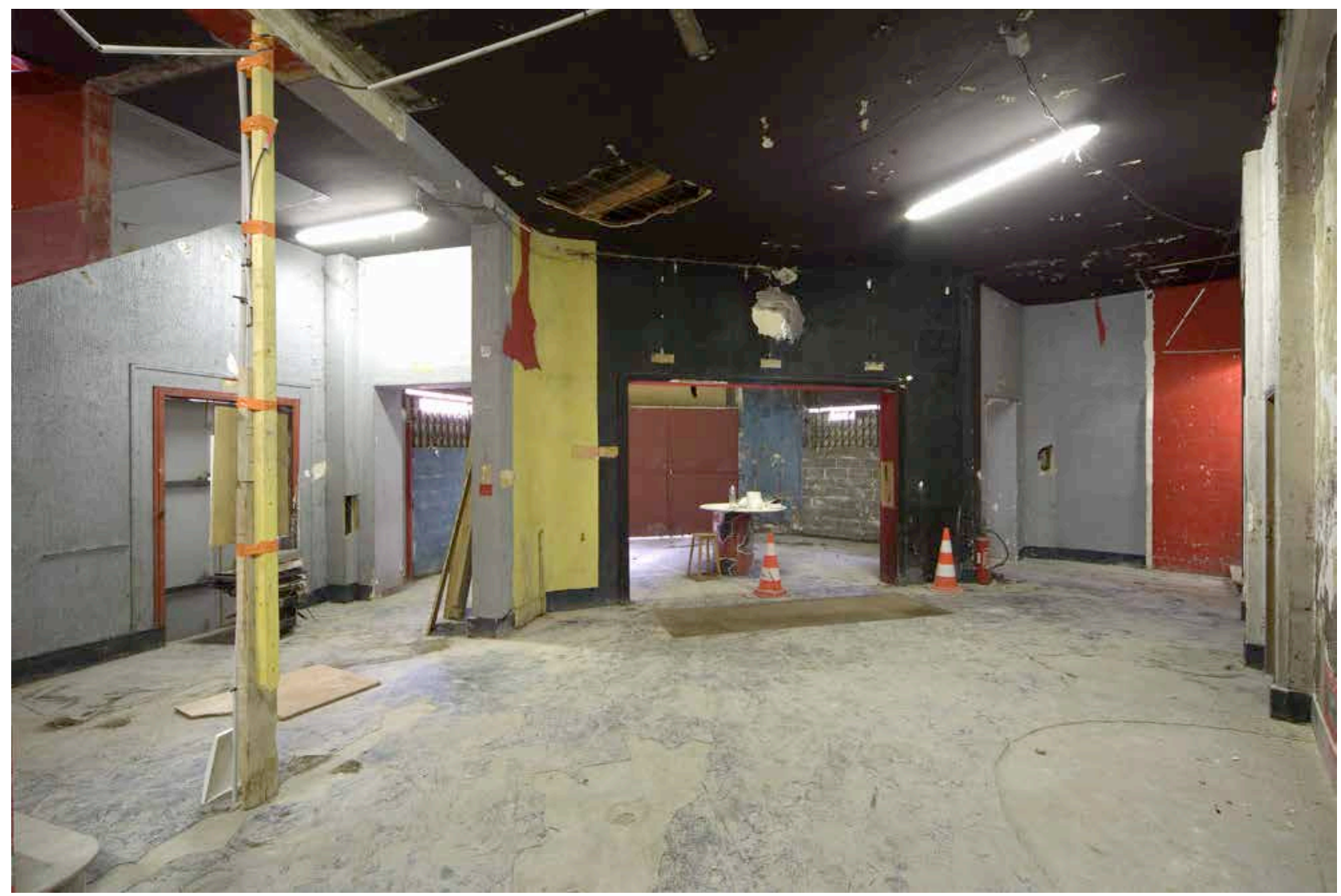

entre noviembre de 2009 y abril de 2010: esta operación permitió localizar la capa freática utilizable, a una profundidad de entre $65 \mathrm{~m}$ y $80 \mathrm{~m}$, y se identificó con precisión la dirección y la dimensión del flujo disponible, con lo cual fue posible modelizar los datos para demostrar tanto la factibilidad técnica de captación, como tam- bién el nivel de seguridad en términos ambientales. En vista de que el flujo óptimo deseado, de aproximadamente $26 \mathrm{~m} 3 / \mathrm{h}$, pudo ser alcanzado ya en la primera perforación, la opción de geotermia fue validada y se procedió a programar una segunda perforación a realizar durante la campaña de la obra principal, esta vez a unos treinta

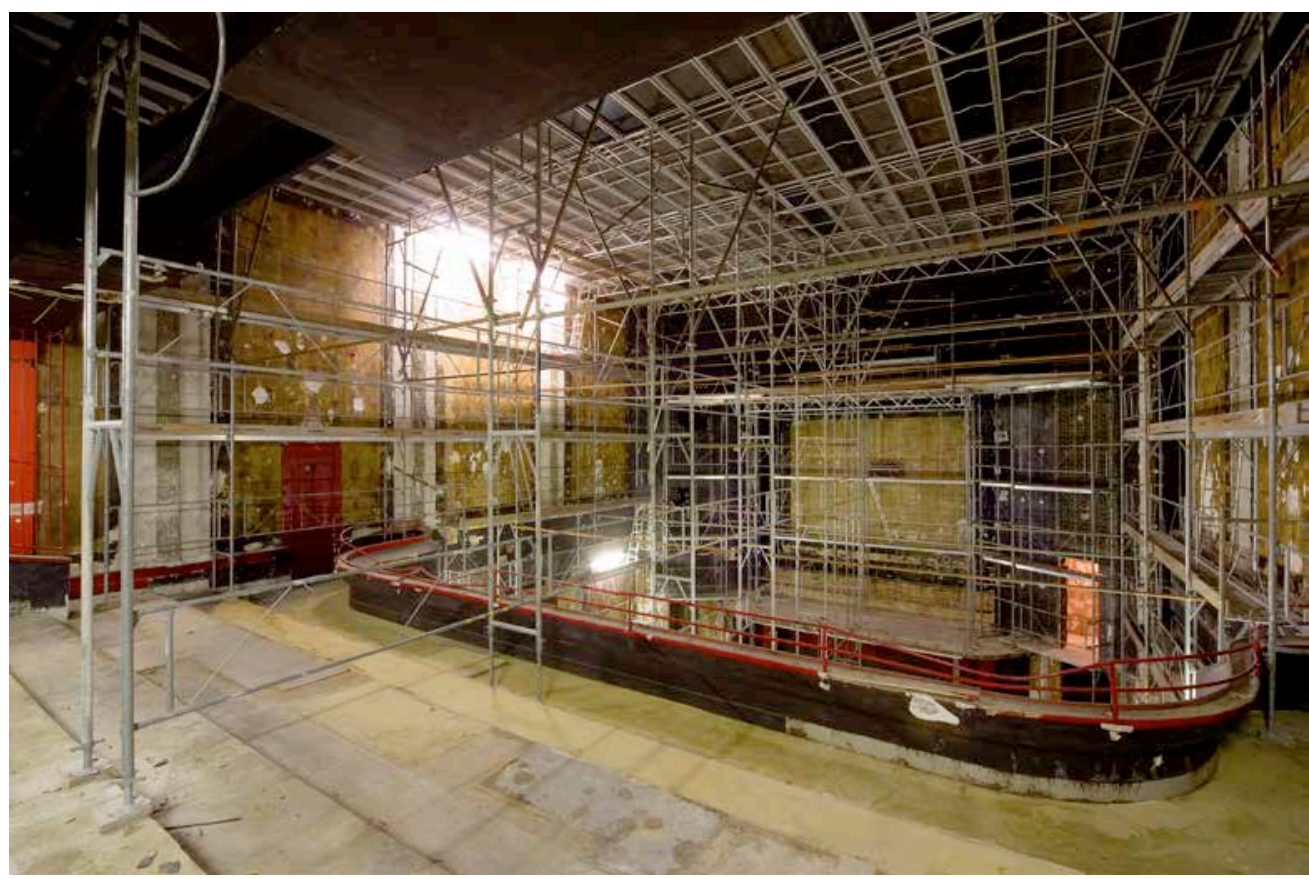

Figuras 24 y 25

(página anterior).

Estado de la gran sala del Louxor tras los trabajos de remoción de los revestimientos añadidos en los años 1950 y 1980.

(Fotografías: Pascal Dhennequin)

Figuras 26 y 27

(en esta página).

Vista del hall durante la campaña previa de limpieza (arriba), $y$ andamiaje en la gran sala durante la campaña patrimonial (abajo). (Fotografías: Pascal Dhennequin) 
Figura 28. Tramo tomado como modelo para la restitución del decorado original de 1921.

(Fotografía: Yves Marchandy Romain Meffre)

11. Trabajo fotográfico de Jean-François Chaput.

12. Trabajo fotográfico de Virginie Laurent.

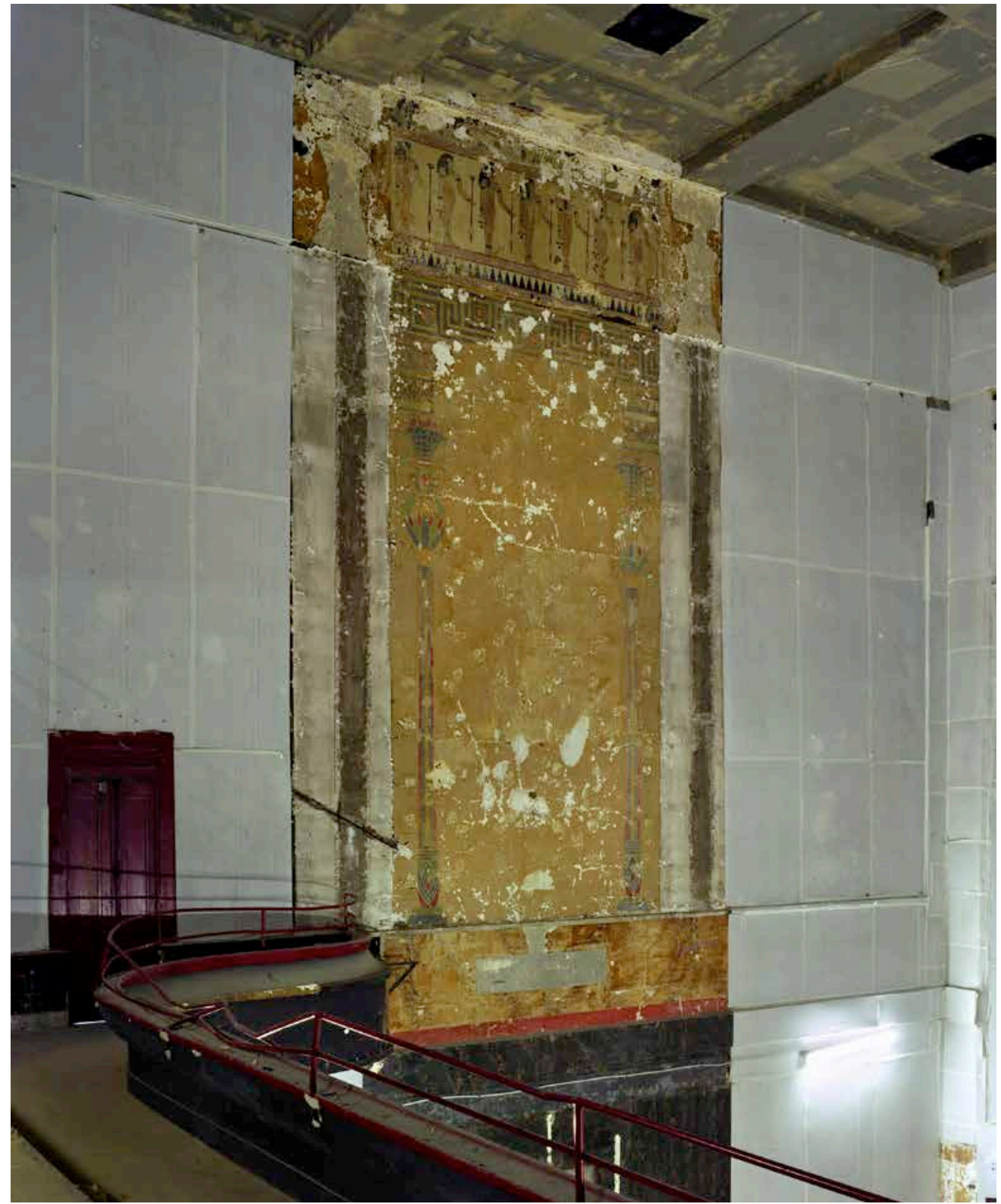

metros de la primera para así completar el binomio : captación-reinyección. La modelización de la instalación de captación y de reinyección mostró además que la utilización de un binomio de este tipo creaba una interferencia térmica globalmente inexistente durante el año: la capa freática, cuya temperatura media alcanza los $15^{\circ}$ $\mathrm{C}$, pierde casi tres grados durante la explotación invernal como consecuencia de la producción de calor, grados que recupera en la explotación estival debido a la producción de frio.

\section{La obra principal}

La obra inició formalmente en septiembre de 2010 y duró casi treinta meses. Teniendo en cuenta la duración prevista de la obra y su localización estratégica en la intersección de Barbès, se decidió emplear una valla y una lona decoradas, con el fin de valorizar el proyecto suministrando una información completa sobre su restauración, tan largamente esperada por los habitantes del sector y de la ciudad en general. Varias series de fotografías fueron expuestas sobre la superficie de la valla mostrando entre otras cosas: imágenes antiguas del Louxor desde los años 1920 hasta su cierre; un reportaje sobre la última proyección que tuvo lugar el 29 de noviembre de 1983'1 retratos de personas que trabajaban en la obra ${ }^{12}$. La complejidad de la obra requirió la intervención coordinada de varias decenas de grupos profesionales especializados, y durante el transcurso 

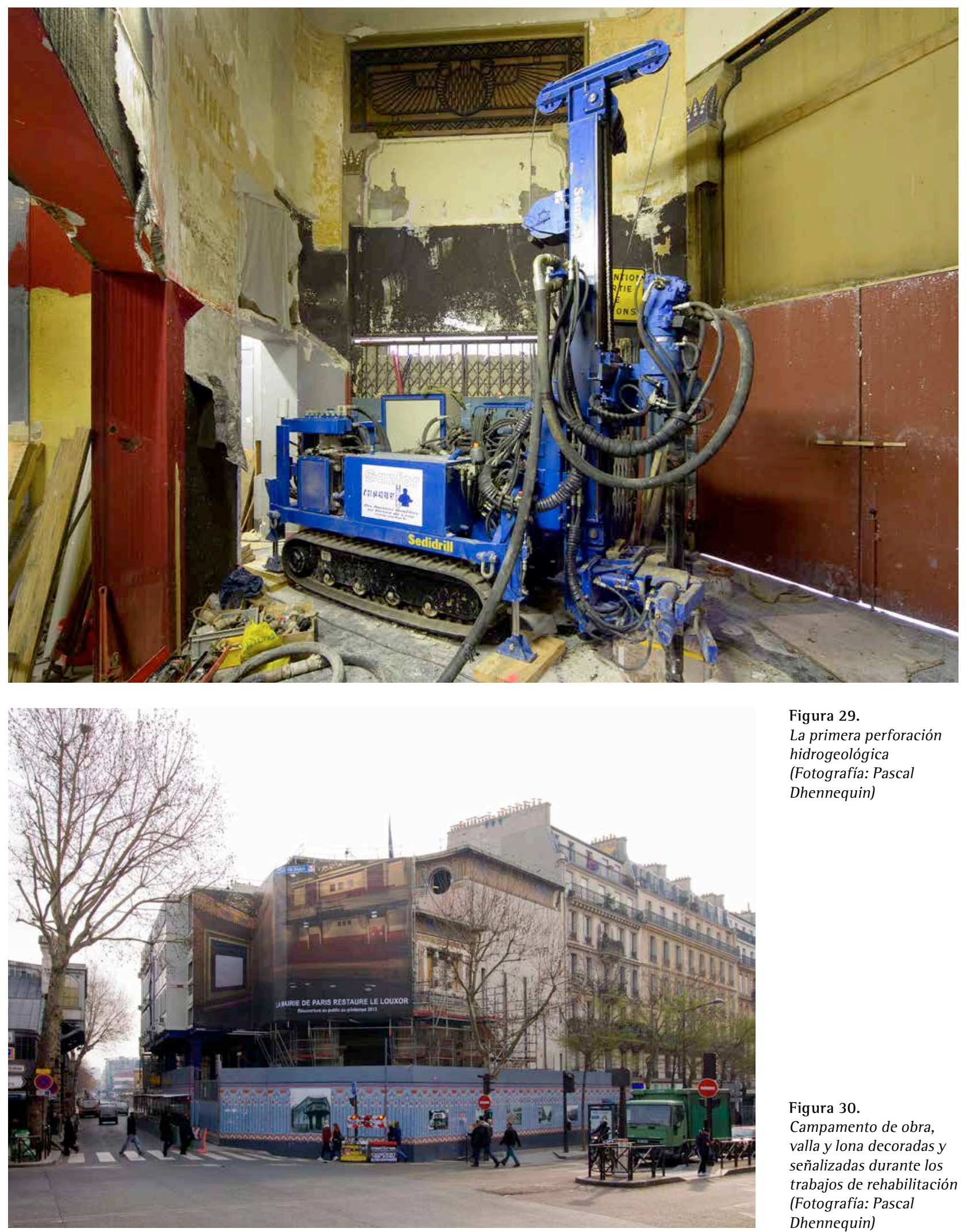

Figura 29.

La primera perforación hidrogeológica (Fotografía: Pascal Dhennequin)

Figura 30.

Campamento de obra, valla y lona decoradas y señalizadas durante los trabajos de rehabilitación (Fotografía: Pascal Dhennequin)

de esta se facilitó la visita de grupos de vecinos del sector y de asociaciones de diversa índole. Entre los ilustres visitantes que se interesaron por conocer de cerca el desarrollo de los trabajos de rehabilitación del Louxor, podemos citar al director de cine Michel Gondry y al reconocido actor Jamel Debbouze quien vivió su infancia en el sector. 
Las demoliciones

Dado que las fachadas del Louxor requerían de una protección especial por el hecho de estar inscritas como Monuments Historiques, y que el edificio posee muros medianeros con otros inmuebles, los trabajos de demolición debían realizarse con las mayores precauciones para no generar daños ni en las estructuras existentes del Louxor, ni por supuesto en aquellas de los edificios vecinos. Un sistema de apuntalamiento en metal y en madera, y de reforzamiento de muros fue instalado previamente a las demoliciones, y adaptado constantemente a lo largo

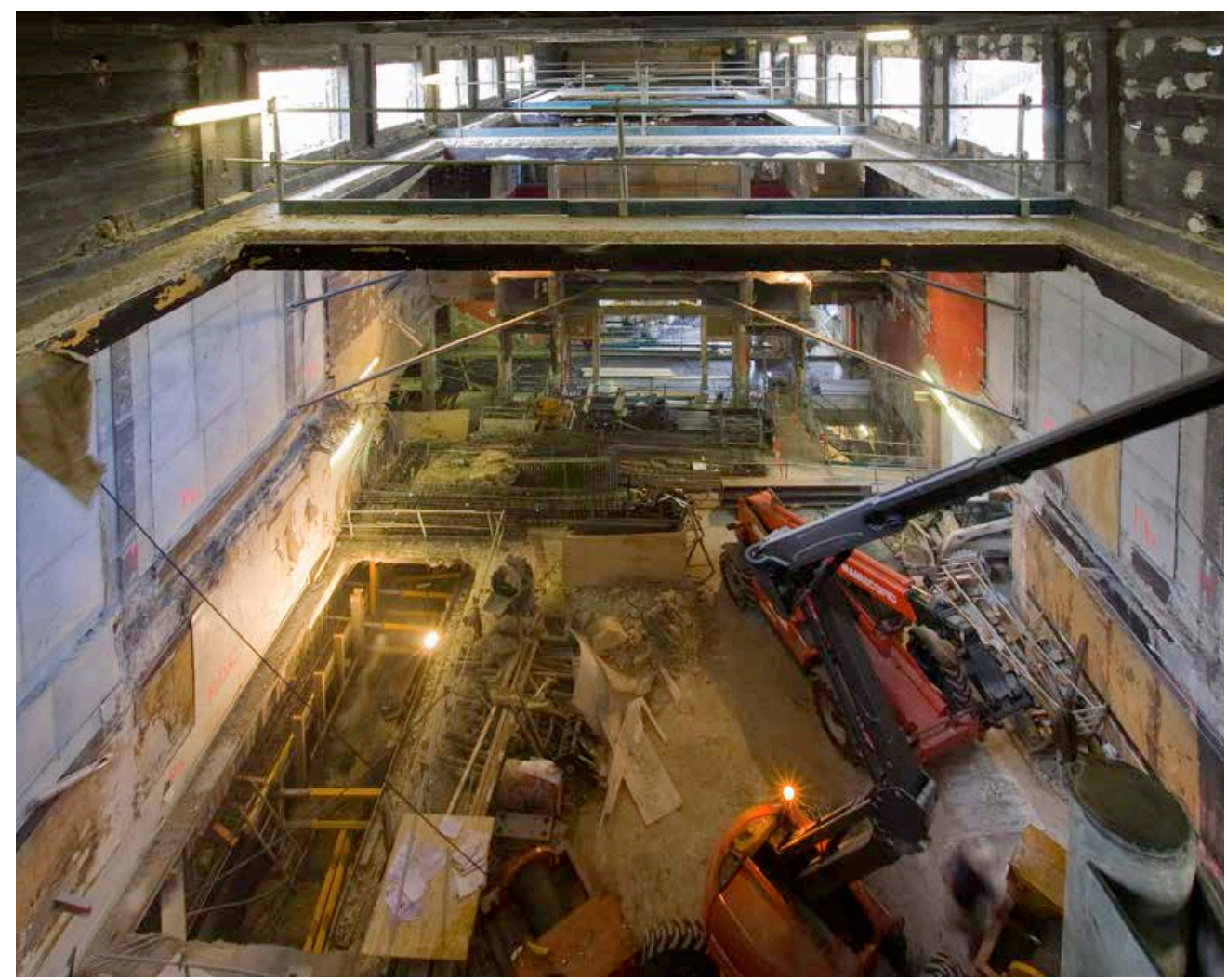

Primeros trabajos de demolición interior (Fotografía: Pascal Dhennequin)

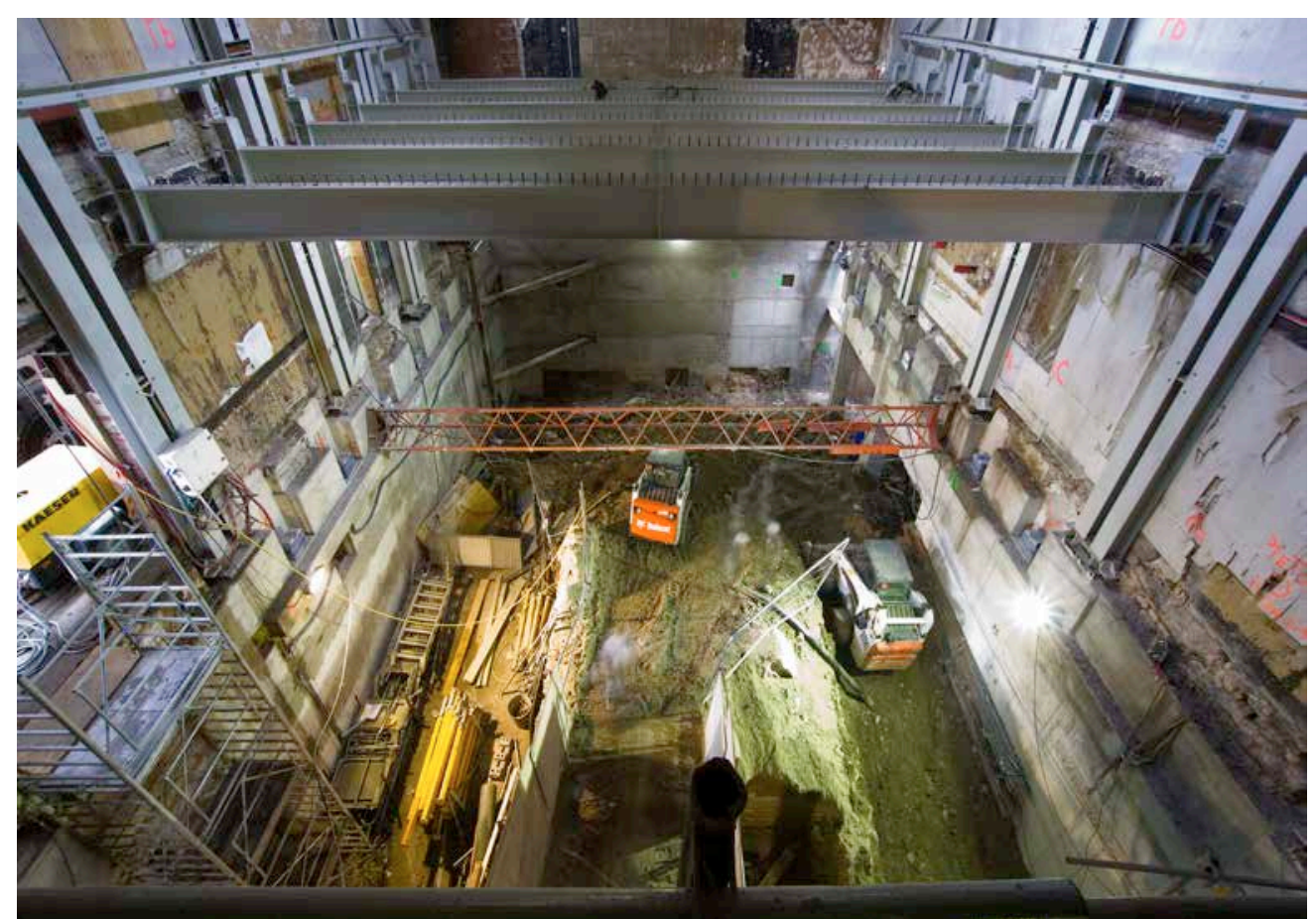

Figura 32. Demolición de los sótanos del antiguo inmueble haussmaniano y reforzamiento de los muros existentes (Fotografía: Pascal Dhennequin) 
de esta fase de trabajos tan delicados. Durante esta fase de la obra se descubrió que el segundo nivel de sótanos del inmueble haussmaniano sobre el cual fue construido el Louxor, había sido reconstruido en 1920 y que toda la zona central había sido rellenada con escombros justamente para la construcción del nuevo cinema, con lo cual se comprobaba tardiamente que esto no era un terraplén tal y como los sondeos y levantamientos previos habían hecho suponer. Dicho descubrimiento fortuito exigió entonces una adaptación in situ de la metodología de demolición programada con lo cual se complicaba el desarrollo de los trabajos.

\section{Los trabajos de cimentación}

Debido a la presencia de antiguas canteras de yeso allanadas, en la zona donde se localiza el Louxor, y con el propósito de cumplir con las exigencias estructurales reglamentarias propias de este tipo de equipamiento destinado a recibir público, fueron realizados trabajos de de cimentación profunda para instalar 175 micropilotes perforados a una profundidad de aproximadamente 22 metros, sobre los cuales se ubicaron 35 pozos de cimentación en hormigón armado repartidos en la periferia del sitio y en la parte central para así recibir las cargas de los muros existentes, a lo cual

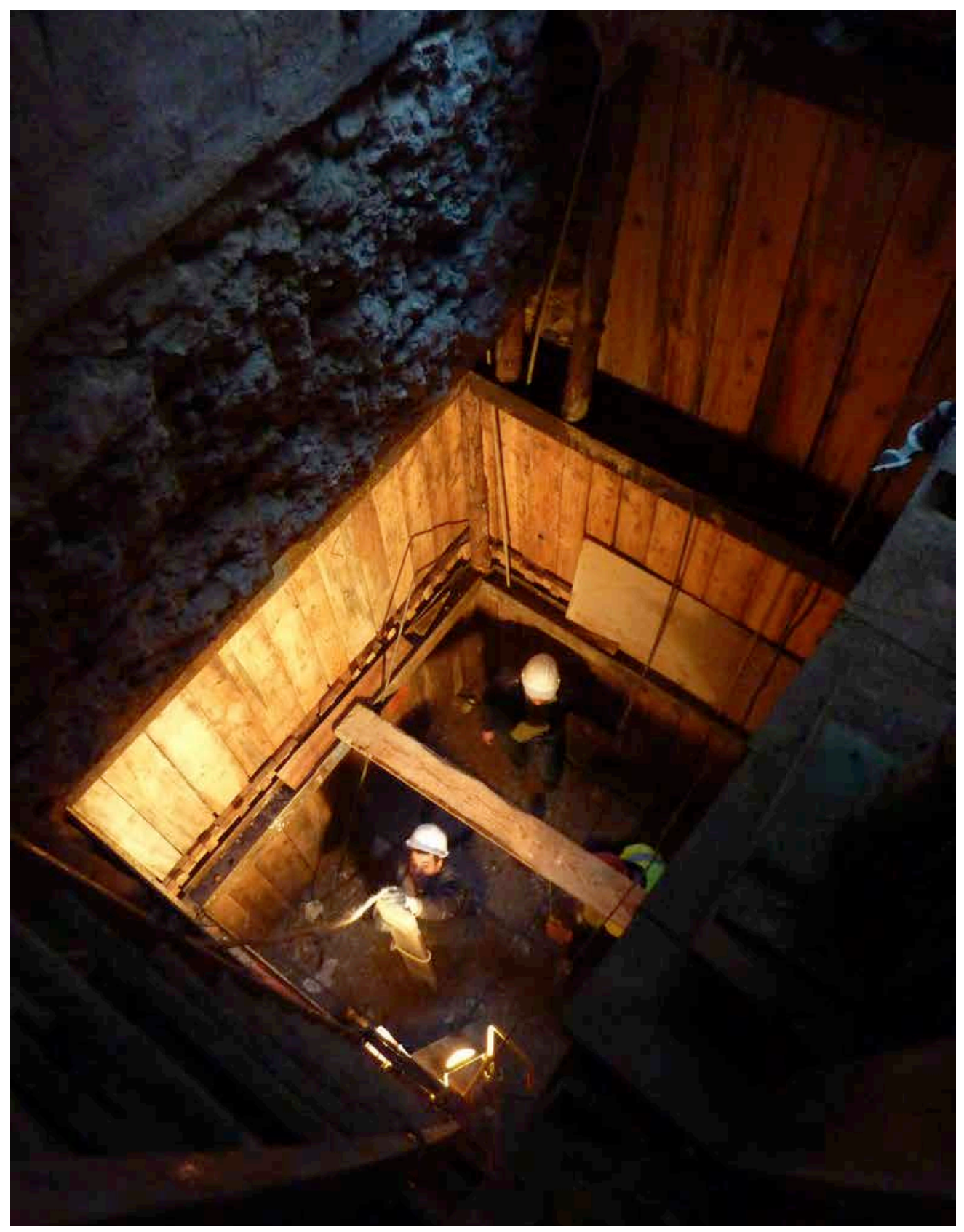




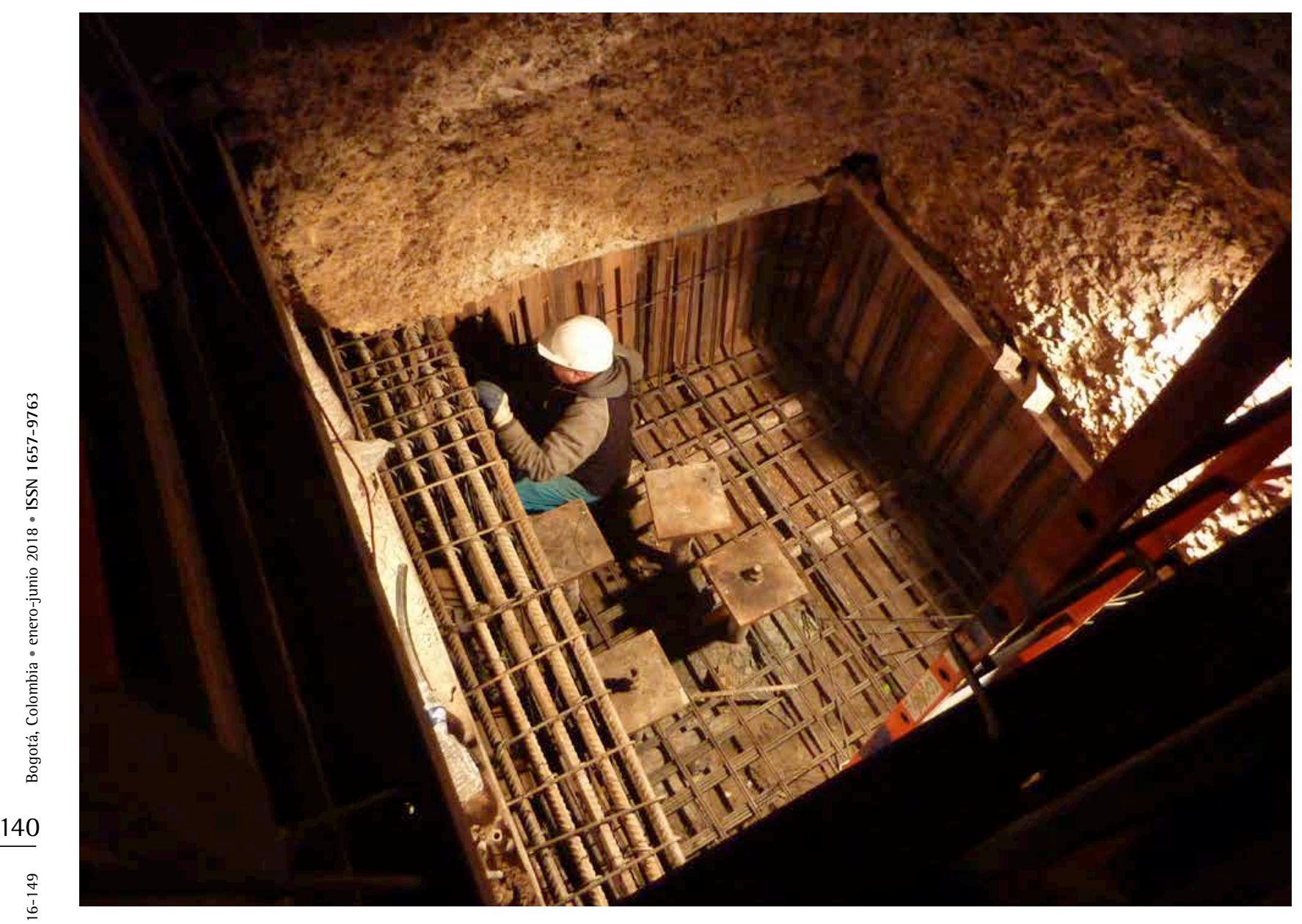

Figura 33 (página anterior) y figura 34

(en esta página). Trabajos de

cimentación previos a la rehabilitación, en donde se aprecian las cabezas de micropilotes.

(Fotografías:

Philippe Pumain) se sumarian las nuevas estructuras proyectadas. Los trabajos de cimentación para los muros periféricos se hicieron de manera alternada: nunca se construían dos pozos contiguos simultáneamente, con lo cual se reducía el riesgo de hundimiento y de agrietamiento. Por último, una red de vigas en hormigón armado venía a conectar la totalidad de los pozos, conformando así el asiento de los diferentes elementos de la superestructura.

\section{La obra principal y la insonorización}

Recurriendo a nuevos cimientos, algunas estructuras interiores fueron construidas en diversas fases. Primero fueron hechas en hormigón armado las placas y muros periféricos de las dos nuevas salas cerradas en el sótano, al igual que los elementos de la cabina de proyección. Al interior de dichas envolventes, cada sala está constituida por una estructura autoportante en Megastil ${ }^{\circledR}$ armazón metálica recubierta con placas de yeso - que reposa sobre muelles para así impedir toda transmisión de sonido de una sala hacia la otra o hacia las edificaciones vecinas. Por encima de las envolventes en hormigón armado de estas dos salas, fueron distribuidas varias decenas de cajas de muelles que sirven de apoyo a la estructura metálica de la caja acústica de la gran sala Youssef Chahine. Este " cubo al interior de otro cubo " está aislado totalmente de las estructuras existentes, excepción hecha de los apoyos sobre las cajas de muelles cuyo rol consiste justamente en evitar la transmisión de cualquier clase de vibración hacia los muros periféricos. La estructura metálica de la gran sala integra la estructura de los balcones -reconstruidos fielmente según los originales- $y$ la estructura del techo artesonado que también fue reconstituido. Posteriormente, los cuatro muros laterales recibieron una mampostería pesada que contribuye al perfecto aislamiento acústico de la gran sala. El resto de la insonorización del edificio se realizó de manera más convencional debido a que las exigencias acústicas concernian sobre todo las tres salas y sus respectivas cabinas de proyección. Algunos espacios como el pórtico cubierto o la escalera histórica en fachada, el hall de recepción o el foyer/sala de exposición situado sobre el pórtico, recuperaron sus disposiciones 


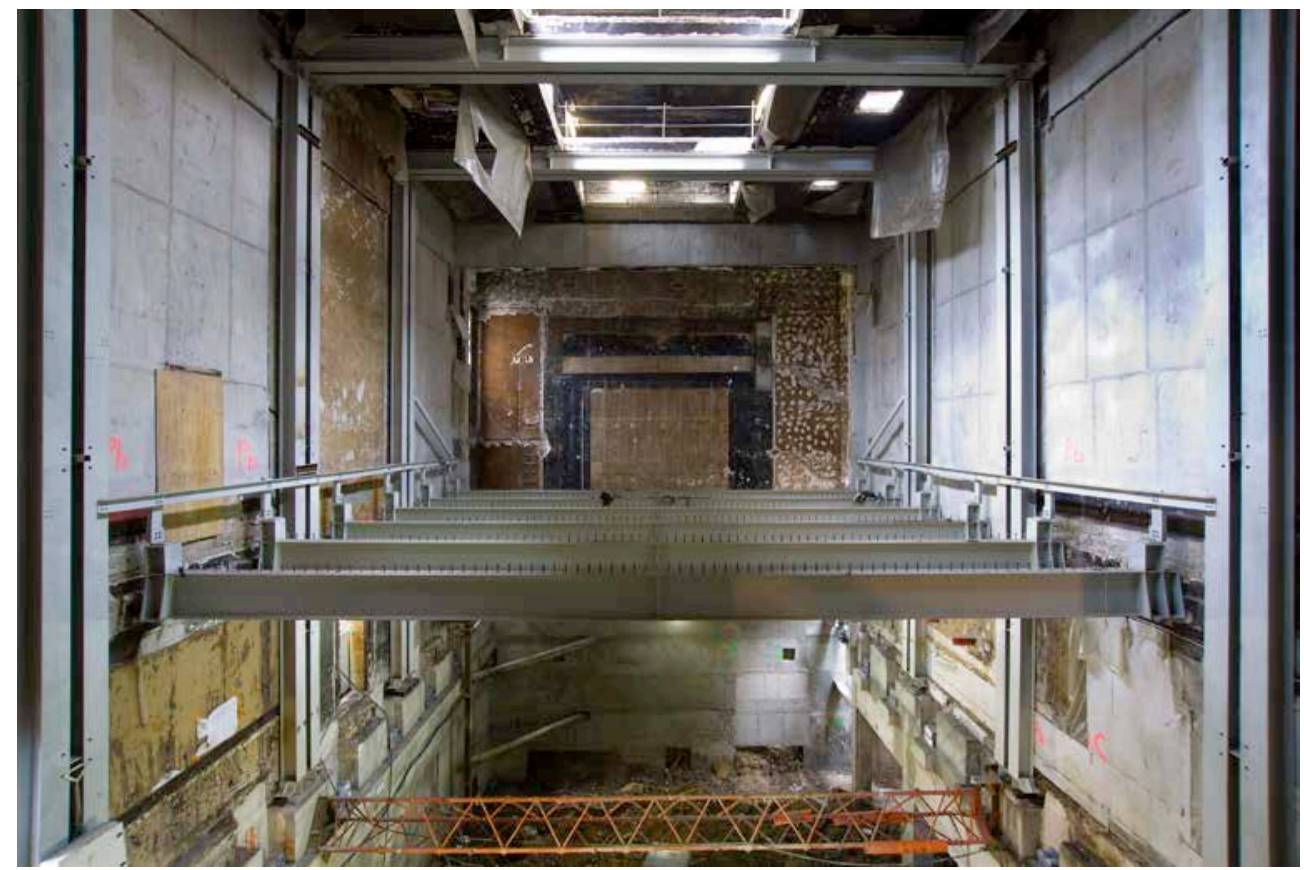

Figuras 35 y 36 (en esta página) y 37 (siguiente página). Tres etapas de la construcción del " cubo al interior de otro cubo ", en la gran sala (Fotografías: Pascal Dhennequin)

originales, alteradas en menor o mayor medida con el paso de los años. Otros espacios fueron remodelados en el marco del proyecto para albergar nuevos usos, tal y como sucedió con el bar instalado en la parte más alta del segundo balcón -el cual no podía ser utilizado de acuerdo a lo dispuesto en las normas actuales sobre la visibilidad de los espectadores-, o como sucedió también con las oficinas instaladas en el espacio que ocupaba antiguamente un alojamiento para empleados en el último piso.

La restauración de las fachadas

Luego de haber sido depuradas eliminando numerosos elementos indeseados (soportes de avisos publicitarios, cables eléctricos y telefónicos), las fachadas, que habían sido pintadas en repetidas oportunidades a lo largo de décadas, fueron decapadas para sacar a la luz su revestimiento original en granito. Mientras que las pruebas previas hacian suponer que aquel revestimiento característico de los primeros años del siglo XX estaría presente en la totalidad de las fachadas exteriores, se encontró finalmente que la fachada que da sobre el boulevard de Magenta había sido totalmente picada y se había eliminado su revestimiento original con ocasión de una campaña de revoque ejecutada en los años 1950: el revestimiento de granito había sido reemplazado entonces por otro más simple y corriente de cemento recubierto de pintura. Habida cuenta de

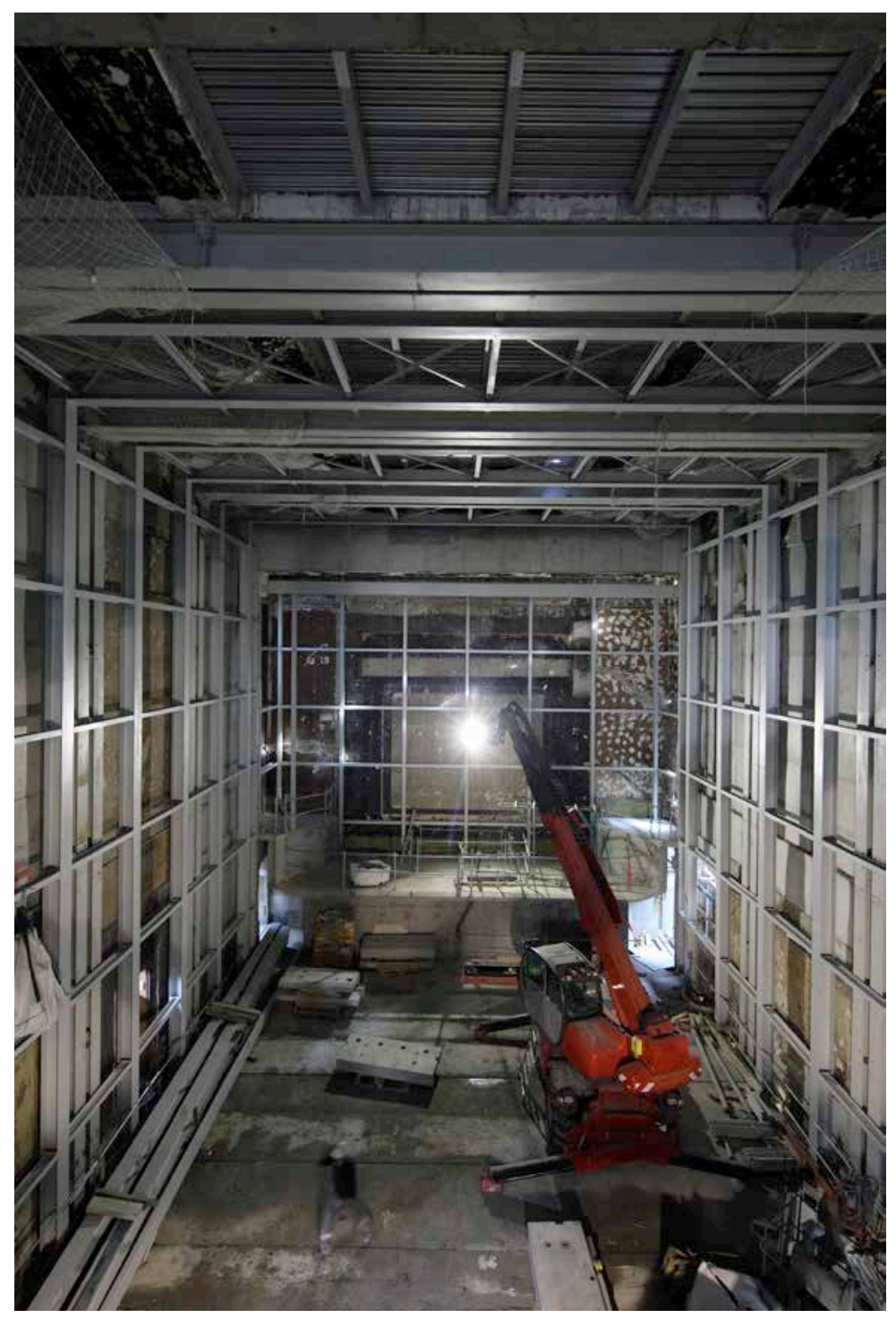




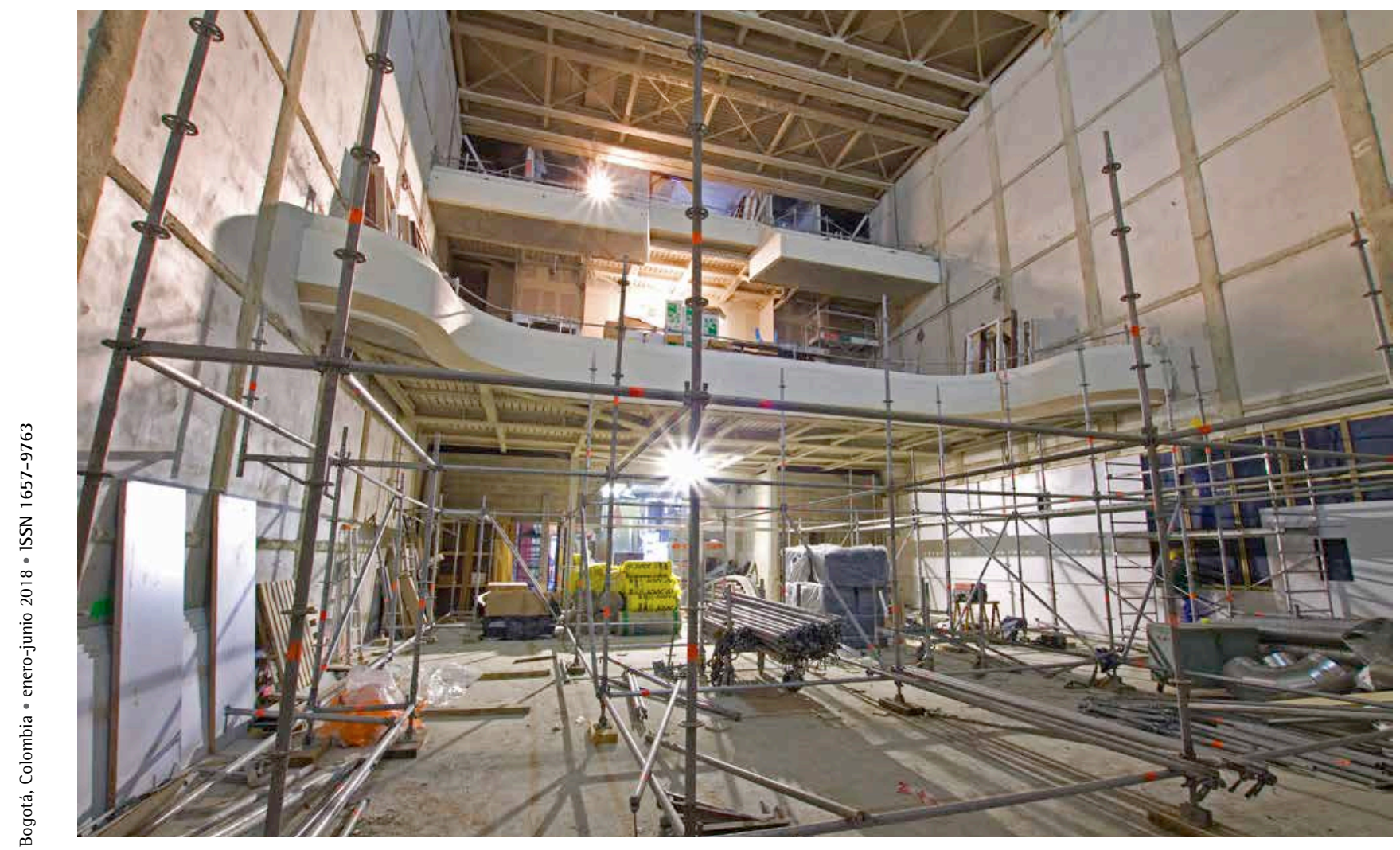

la inscripción del Louxor en el Inventaire Supplémentaire des Monuments Historiques - ISMH, y para mantener la coherencia del conjunto, se dejó constancia de la necesidad de restituir dicha fachada en granito. En cuanto a la fachada en ángulo, y la que se forma sobre el boulevard de La Chapelle, se encontró que el granito aún estaba presente en ellas, oculto bajo las capas sucesivas de pintura aunque fuertemente alterado a causa de las numerosas fisuras y perforaciones debidas en gran parte al paso dado a redes burdamente adecuadas en cemento y pintadas una y otra vez. Para devolver a las fachadas la identidad y la integridad perdidas, debió efectuarse un complicado

\section{Figura 38. Restitución de mosaicos en el gran friso superior de la fachada (Fotografía: Philippe Pumain)}

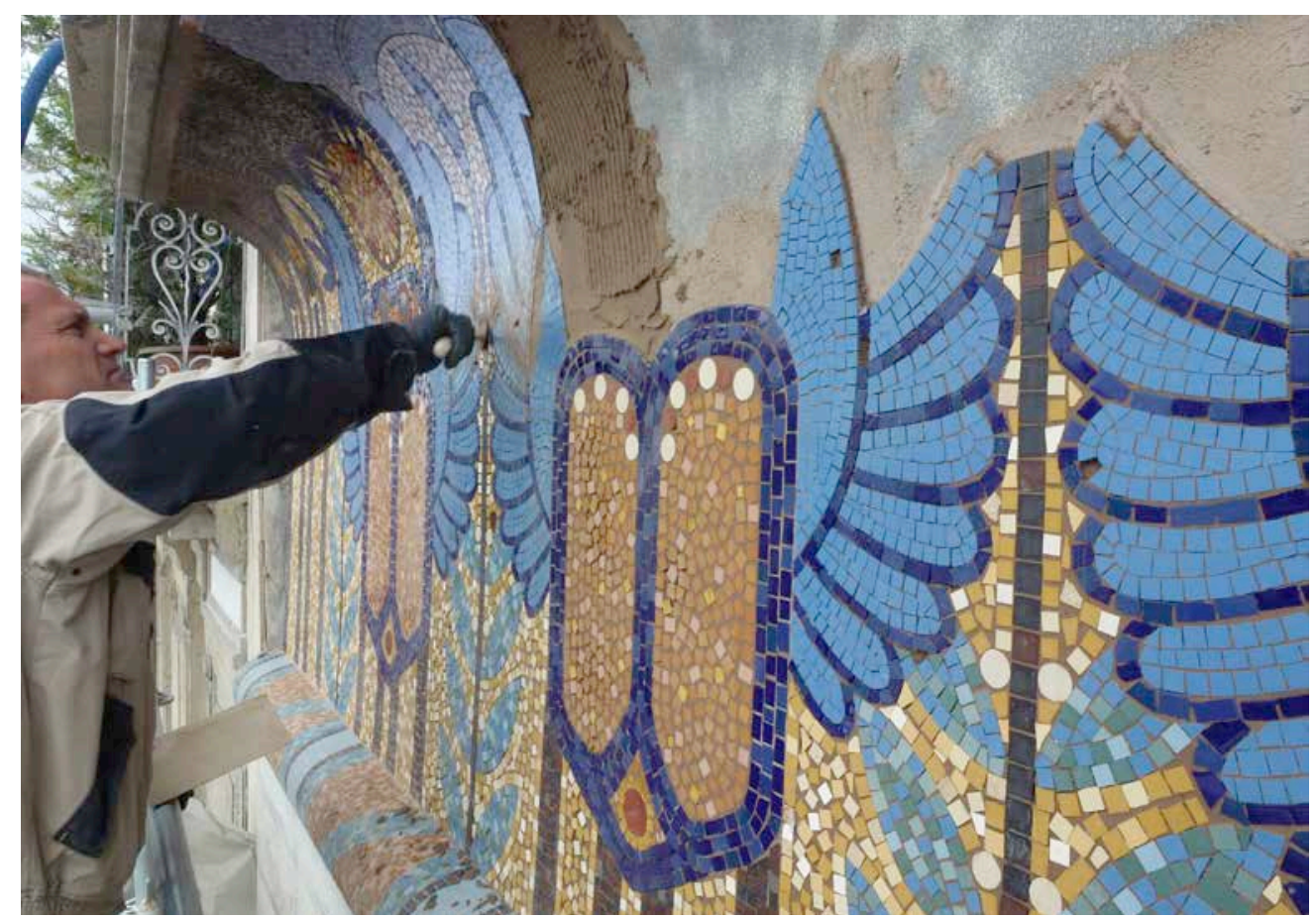



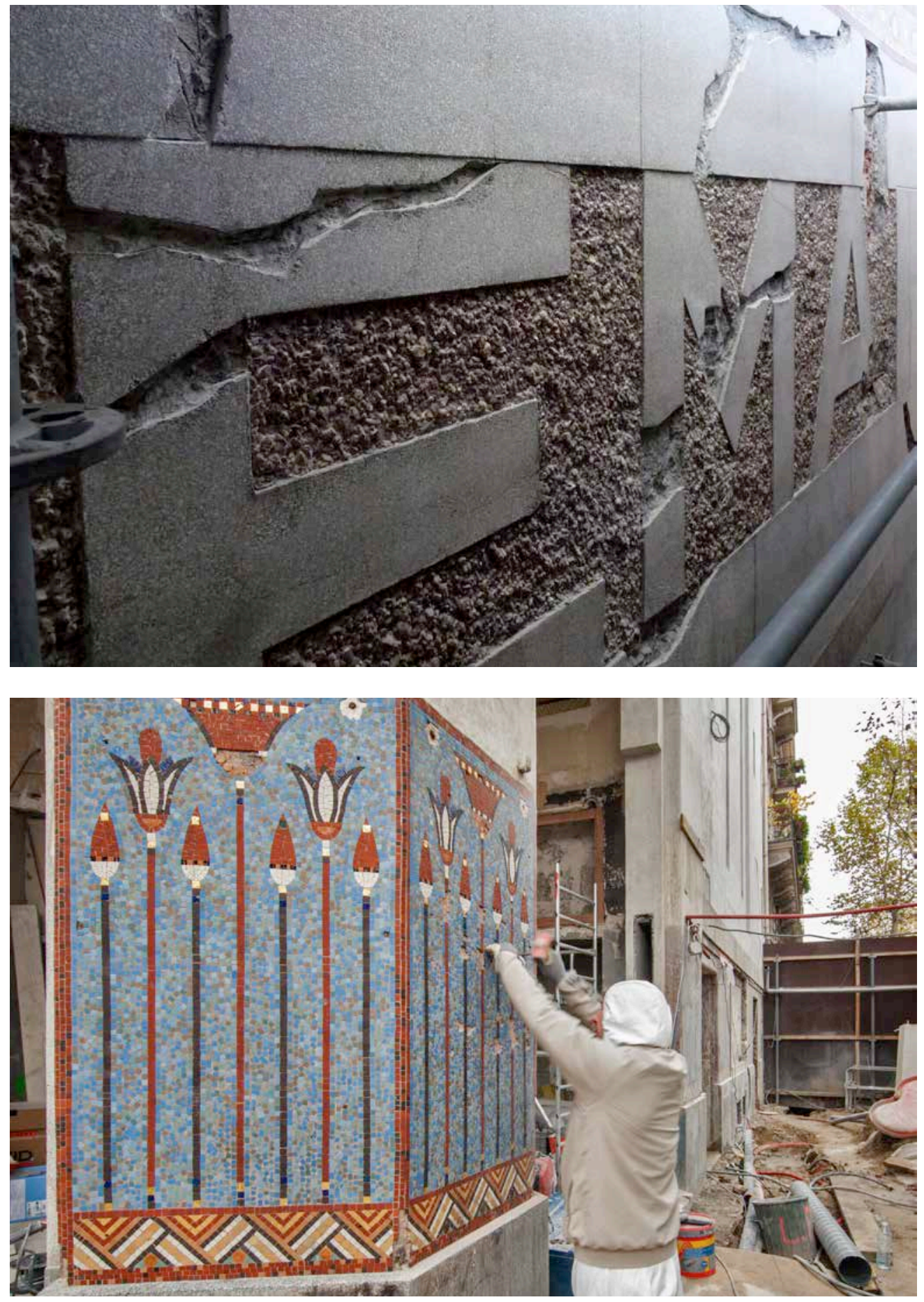

trabajo de reposición, que requirió una investigación previa extremamente precisa sobre la granulometría y la colorimetría para de esta manera asegurar la calidad de los trabajos a efectuar con la mayor precisión posible (tras un lijado muy fino, se procedió a la impermeabilización de la superficie). Aunque había desaparecido y solo se tenía evidencia de su aspecto por fotografías de la época, la inscripción en granito con el nombre del teatro, LOUXOR, sobre la fachada que da hacia
Figura 39.

Restauración de capas de granito en las fachadas (Fotografía: Philippe Pumain)

Figura 40.

Restauración de los mosaicos de la parte inferior de la fachada (Fotografía: Pascal Dhennequin)

el boulevard de Magenta, fue restaurada sobre un fondo de gruesos granulados en cemento coloreados en un tono castaño-rojizo como en la versión original de 1921, al igual que los mosaicos que hacían parte del conjunto. Por otro lado, la inscripción LOUXOR - PALAIS DU CINEMA, bastante alterada pero aun presente en la fachada que da hacia el boulevard de La Chapelle, también fue restaurada siguiendo los mismos principios. 
Los trabajos exteriores de carpintería puertas, postigos, vanos acristalados - que originalmente eran en madera pintada, fueron restituidos con base en los dibujos y fotos que se conocen de la época. Los mosaicos de la base, que presentaban un buen estado de conservación, fueron restaurados reintegrando elementos faltantes: dichos mosaicos enmarcan las vitrinas exteriores que sirven para anunciar los films programados en las tres salas, y en las cuales se usa una iluminación incorporada tal y como en las vitrinas originales. Hacia el boulevard de La Chapelle, se han restituido los mosaicos de la cornisa superior, los cuales habian sido retirados íntegramente desde los años 1950 : su restitución se hizo siguiendo el modelo de las cornisas conservadas en la fachada en ángulo del boulevard de Magenta. Dichos mosaicos se fabricaron sobre soportes en calcos de poliéster, en un taller especial; mientras que los vitrales que también habían sido eliminados tempranamente a pesar de su importancia dentro de la estética del edificio, se restituyeron tanto en la fachada en ángulo -conocidos gracias a las fotografías antiguas- como también en los dos grandes vanos verticales sobre el boulevard de Magenta, cuya existencia fue descubierta únicamente durante el desarrollo de la obra. La marquesina que se encuentra en el acceso - que sirve a la vez como protección contra la intemperie en el pórtico, y que aporta también una iluminación en la noche -, gravemente degradada y alterada con el paso del tiempo, fue desmontada para ser restaurada en un taller especial, y reinstalada en la etapa final de la obra. Por último, las cuatro grandes astas en madera coronadas con un disco solar que se enciende en la noche, y cuya desaparición se remonta a los años 1940, marcan de nuevo el ritmo de las fachadas del Louxor.

La implantación de los principales equipos técnicos

Los espacios destinados a aparatos y operaciones técnicas ocupan un espacio significativo que representa alrededor del $15 \%$ de la superficie de obra total ${ }^{13}$, especialmente en vista de las necesidades relacionadas con la renovación

13. La superficie de obra, denominada SDO, representa la superficie total del edificio, incluyendo el conjunto de circulaciones, así como lo locales técnicos y los anexos. independientes que, como en el caso de la bomba de calor han debido ser instalados con el uso de grúas, en operaciones realizadas siempre en horarios programados para perturbar lo menos posible la concurridísima circulación aledaña al proyecto en plena intersección de Barbès.

\section{Los decorados interiores}

Los decorados interiores fueron objeto de tres tipos de intervención : por un lado, la restitución del decorado de la gran sala buscando aproximarse al máximo al estado original de 1921 aunque teniendo en cuenta la ligera modificación en sus dimensiones propiciada para crear la caja acústica ; por otro lado, la restauración de los decorados redescubiertos en el pórtico, el hall y la antigua escalera bajo las múltiples capas de pintura añadidas durante años ; y por último, la creación en los nuevos espacios propuestos, de un decorado contemporáneo que presentara relaciones formales con el tema de la egiptomanía, particularmente en las dos salas construidas en el sótano, de las cuales, la sala pequeña debía ser tratada con una bóveda en asa de cesta evocando aquellas presentes en algunas de las tumbas del Valle de los Reyes, mientras que la sala mediana evocaría el tema de la sala hipóstila con dos hileras de columnas laterales para delimitar las zonas de circulación.

En lo que respecta a la gran sala bautizada Youssef Chahine, el decorado original que el público de los años 1920 pudo apreciar apenas durante la primera década de existencia del Louxor -como los elementos neoegipcios (columnas de pequeñas dimensiones, jeroglíficos, cabezas de faraones, etc.)-, intentó ser restituido -con toda su carga de sofisticación- en el marco de los trabajos de rehabilitación del Louxor. Así, se trató de recuperar una serie de elementos entre los cuales sobresalen : la base en imitación de mármol negro que cubre la periferia de la platea, coronada con una franja hecha en imitación de mármol ocre que corresponde al nivel de la baranda del primer balcón; las pequeñas columnas florales que sobresalen sobre un fondo uniforme color beige arenoso coronadas a su vez por un friso de estilo griego bastante anacrónico con relación a la estética egiptizante del edificio; y por último, bajo el techo las dos filas de personajes egipcios que convergen de una y otra parte de la sala, hacia el gran sol alado -suprimido prematuramente pero visible en una fotografía que data de los primeros tados de elementos diferenciados y plenamente y circulación del aire inherentes a un edificio destinado a las proyecciones cinematográficas. Los equipos técnicos voluminosos, como las centrales de tratamiento de aire, han sido do- 
años del Louxor- que sobresalía dominando el escenario y la antigua pantalla.

Las vigas laterales contrastaban con el ritmo marcado por dos pilastras en estuco tratadas como imitación de mármol, las cuales desparecieron también a finales de los años 1920. Un inventario realizado cuando Pathé se hizo cargo del Louxor en 1930 da fe de la presencia de cabezas en relieve coronando las pilastras, que eran sin duda cabezas de faraones similares a las que se distinguen - no sin dificultad - en la única foto histórica disponible de aquella época. Las cabezas de faraón fueron restituidas en estuco moldeado, con la corona atef siguiendo el modelo dibujado por el egiptólogo Émile Prisse d'Avennes (1807-1879), todo ello gracias a los consejos eruditos del especialista Jean-Marcel Humbert (1947- ).

El techo artesonado fue tratado con gran cuidado por cuanto las caras inferiores de las vigas estaban decoradas con motivos florales y cartuchos de jeroglíficos dispuestos formando combinaciones fantasiosas. Grandes elementos en estuco decorados con motivos egiptizantes (buitres, serpientes) ocupaban las vigas del techo en el eje de la sala: realizados originalmente en estuco calado para permitir a la vez la ventilación de la sala y una iluminación cenital -a priori «simbólica»- por medio de lámparas suspendidas en el edículo técnico que corona el techo de la sala, dichos elementos decorativos eliminados progresivamente desde los años 1930 han sido reinterpretados y restituidos bajo la forma de artesones luminosos en metal y vidrio retomando diseños egiptizantes y utilizando diodos electroluminosos como fuente de iluminación.

Durante la campaña de limpieza, fueron encontrados en el pórtico dos bajorrelieves en estuco: una cabeza de faraón, y una representación de la diosa Tefnout sentada: estos elementos fueron restaurados para luego ser instalados a ambos lados de la entrada del Louxor. En el hall de acceso, sobre el muro que se encuentra frente a la entrada fue encontrado otro bajorrelieve en estuco gravemente alterado, al cual se le dio un tratamiento especial y se tomó de él una reproducción, para luego ser reinstalado en su ubicación original.

Otros elementos del decorado fueron restaurados y/o completados cuando fue necesario, y entre estos sobresalen : los muros del pórtico exterior, con un friso vegetal en la parte superior y sobre la cornisa del techo ; el muro del hall ubi- cado en frente de las puertas de acceso al edificio, tratado en imitación de mármol ocre, y en el cual se integró el bajorrelieve encontrado; la escalera principal conservada, sobre la fachada que da al boulevard de Magenta, con un decorado de falsas juntas en piedra y marcos de vanos realzados por boceles egipcios.

El renacimiento de un cinema excepcional

El pórtico exterior, reintegrado al espacio público durante las horas de funcionamiento del cinema y clausurado en horas de la noche por medio de rejas extensibles, organiza el acceso al hall en donde son recibidos los espectadores para ser orientados hacia las diferentes salas. Este hall ha recuperado su geometría así como los principales elementos de su decorado original (puertas en madera de tono caoba, pared en imitación de mármol, bajorrelieve de estilo egipcio, etc). Además, como sucede en los principales espacios del edificio -el foyer/sala de exposiciones, el bar, los balcones-, el revestimiento del piso, de cuyos materiales originales no existía vestigio alguno salvo por una pequeña parte del pórtico, ha sido tratado con mosaicos en gres cerámico de dos centímetros de largo formando un friso geométrico que recorre la periferia, en una clara inspiración Art déco.

Desde el hall, los espectadores pueden acceder directamente a la platea de la gran sala, o subir a los balcones utilizando la nueva escalera que comunica también con el foyer/sala de exposiciones situado en la tercera planta, y con el bar situado en la cuarta planta. La antigua escalera completa el dispositivo de circulación, y cumple su función para la evacuación en caso de emergencia. El acceso a las dos salas del sótano se hace igualmente desde el hall por la escalera principal y se completa con tres escaleras de emergencia. Tal y como sucede con la antigua escalera restaurada, los tramos de la nueva escalera han sido recubiertos con granito. Estas dos escaleras principales cuyos vanos dan hacia el exterior, y que habían sido clausuradas previamente con muros, gozan de nuevo de una iluminación natural al igual que los pasillos de cada una de las plantas. Todos los niveles son servidos por un ascensor reservado a las personas de movilidad reducida.

La gran sala Youssef Chahine cuenta con 342 plazas -334 sillas y 8 sitios reservados a las personas en silla de ruedas- de las cuales 192 se encuentran en la platea, 116 en el primer balcón y 
14. Tipo de pantalla que se enrolla sobre un cilindro situado en la parte baja y que vuelve a subir gracias a un mecanismo de accionamiento motorizado.

Figura 41. Vista de la gran sala, hacia el balcón

(Fotografia/ Art Graphique et Patrimoine)
34 en el segundo balcón. Esta sala cuenta además -como en su origen- con un pequeño escenario que permite recibir a directores, actores u otros invitados que acudan con motivo de preestrenos o de festivales. Bajo el escenario ha sido restituido el foso de orquesta en donde un pianista o un pequeño grupo de músicos pueden acompañar la proyección de films mudos que se presenten sobre la pantalla de seis metros de largo que ha sido pintada directamente sobre el muro, como sucedía al momento de la inauguración del Louxor en 1921. La sala dispone además de una pantalla retráctil [enroulable à la polichinelle ${ }^{14}$ ] de nueve metros de largo que responde a los estándares actuales, y que puede plegarse totalmente sobre el escenario gracias a una compuerta localizada sobre este. Los altavoces principales que hacen parte del sistema de sonido y que se encuentran ubicados detrás de la pantalla, también son retráctiles, y los parlantes periféricos que complementan el sistema son disimulados tras el decorado de la sala para así respetar la integridad de este. Junto a las nuevas sillas, enteramente rediseñadas, se implantaron en el segundo balcón tres sillas antiguas, como un guiño a la sala de los años 1920 permitiendo al público dimensionar la evolución del confort tras la creación del Louxor. Los materiales absorbentes utilizados en el revestimiento - membranas flexibles en madera y mortero microporoso a base de polvo de mármol y de vidrio para los muros, alfombra para el piso, sillas recubiertas con terciopelo - contribuyen a una excelente audibilidad a pesar del volumen atípico de la sala. La iluminación se dispuso esencialmente en el techo gracias a artesones luminosos centrales, como también a un conjunto de lámparas laterales inspiradas en el diseño de los dispositivos originales del Louxor. La cabina de proyección está equipada con un proyector digital $4 \mathrm{~K}$ que ofrece una óptima calidad de imagen, y otro proyector de $35 \mathrm{~mm}$.

La sala mediana situada en el sótano, y que cuenta con 140 plazas - 136 sillas y cuatro sitios reservados para personas en silla de ruedas- es la única de las tres salas prevista para albergar ocasionalmente otras actividades diferentes a las proyecciones cinematográficas. Esta sala, dotada de un escenario (aprox. $8 \mathrm{~m}$ por $4 \mathrm{~m}$ ) y de un pequeño camerino, está adaptada para pe-

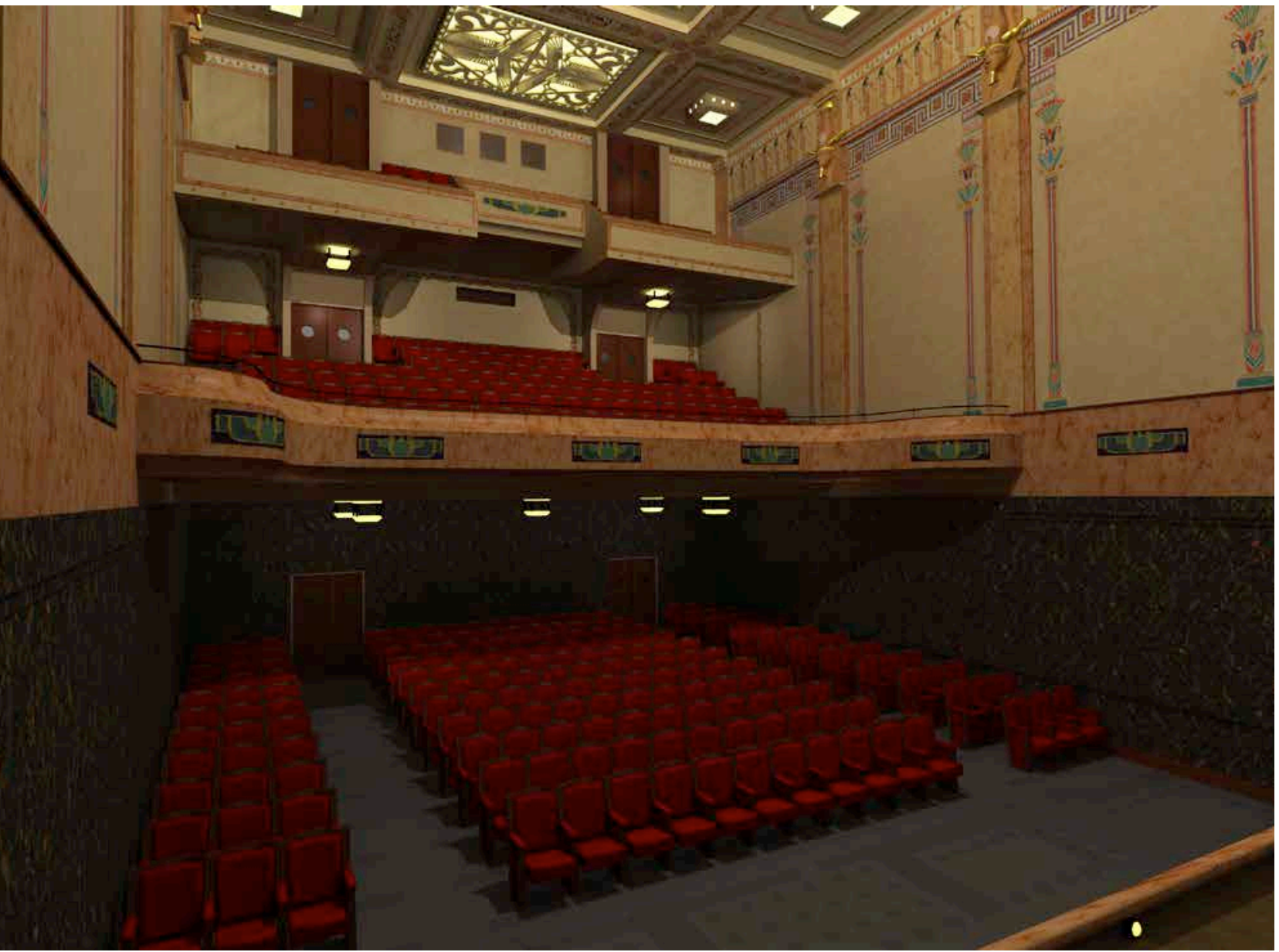




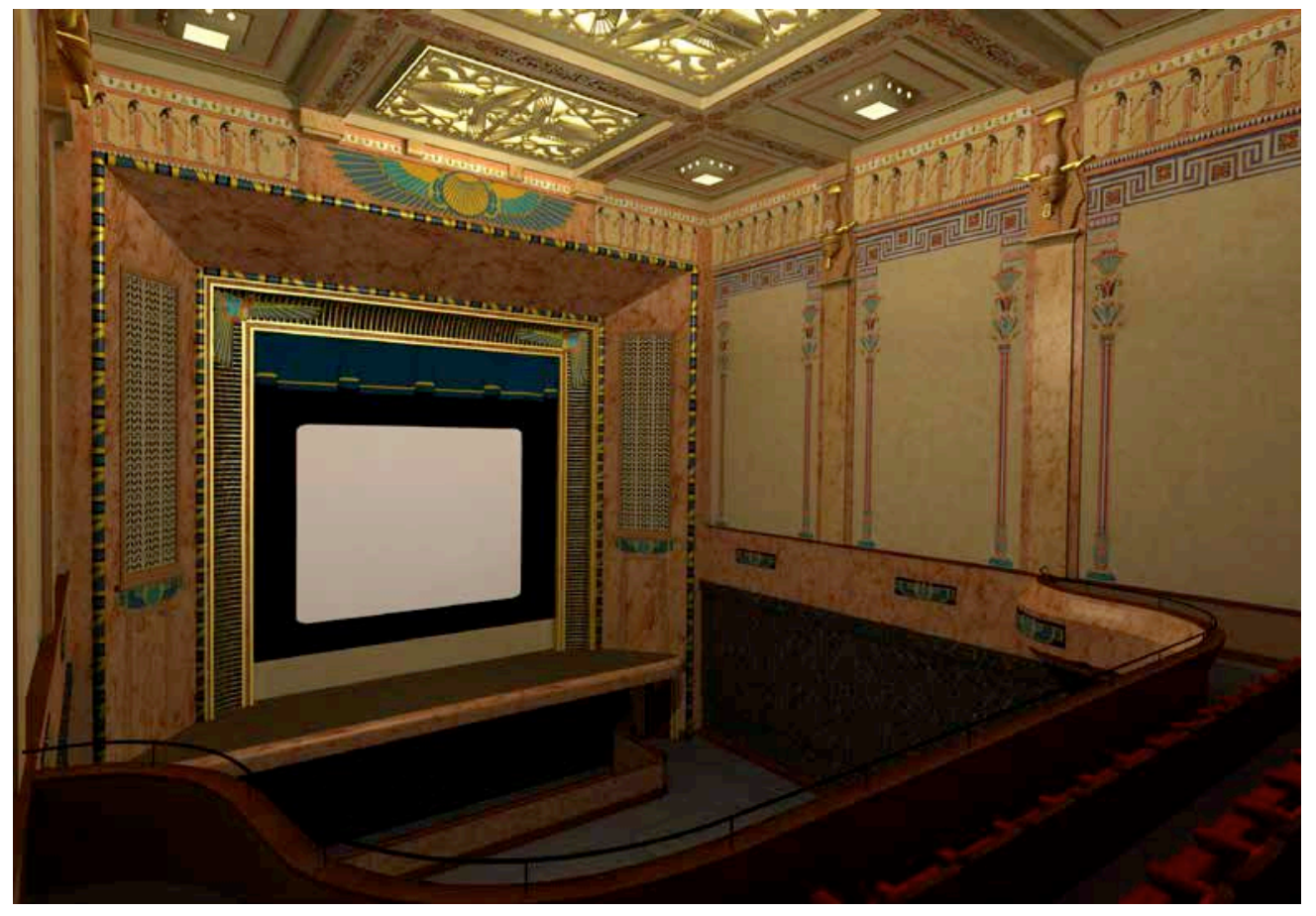

Figuras 42 y 43.

Vista de la gran sala

con la pantalla pequeña

(arriba), y con la pantalla

grande (abajo).

(Fotografías: Art

Graphique et Patrimoine)

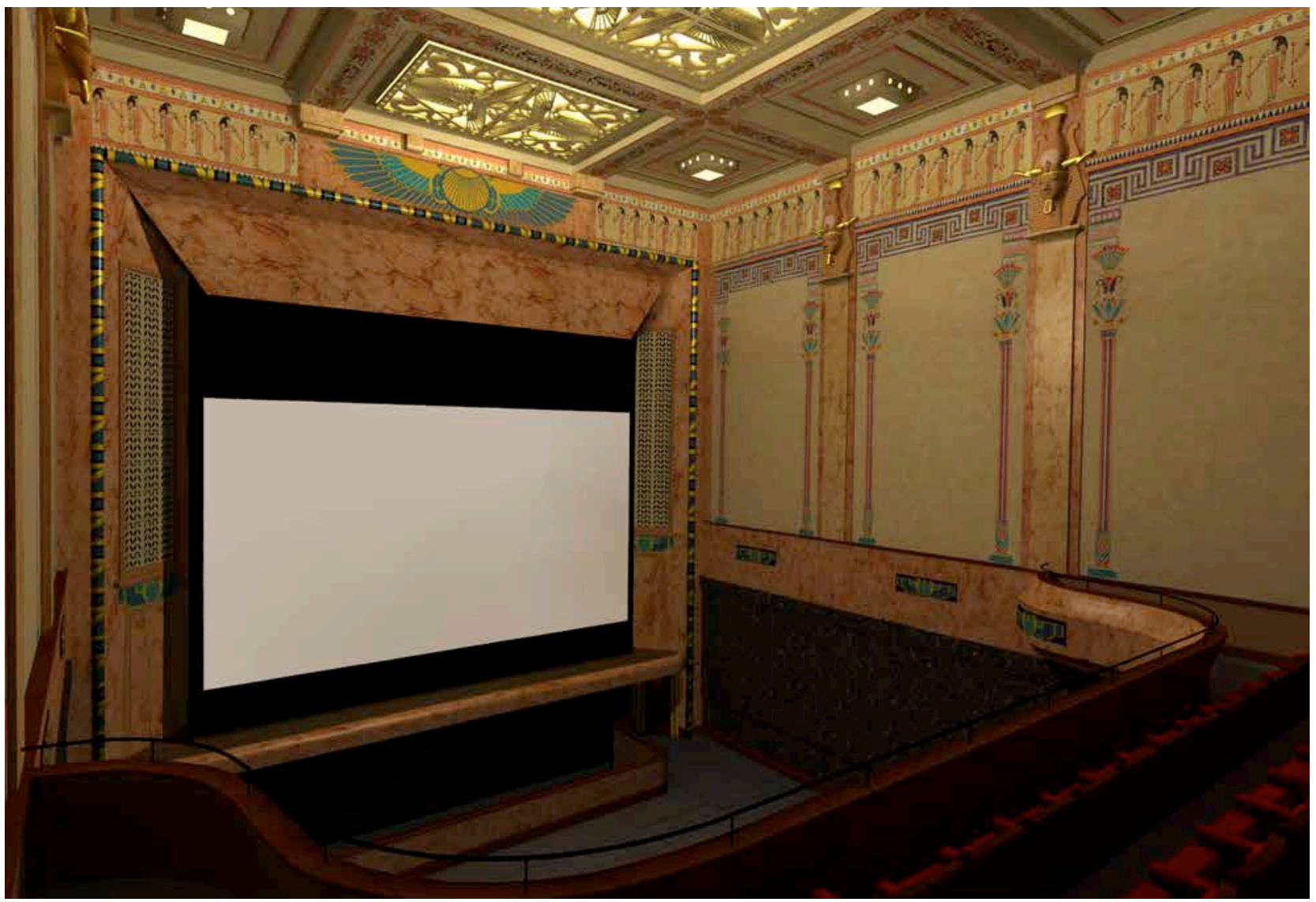

queñas manifestaciones de espectáculos en vivo, particularmente musicales. Las sillas en madera oscura y en terciopelo marrón están dispuestas sobre un piso en parquet y delimitadas por dos hileras de columnas color bronce. Las paredes también llevan un terciopelo marrón, y el techo que representa un cielo estrellado constituye un homenaje a este tema egipcio clásico. En esta sala se instaló una pantalla fija de 7,30 metros de largo; y la cabina de proyección -que comparte 
Figuras 44 y 45. El Louxor, días después de su reapertura en 2013,

tras la rehabilitación descrita en el presente artículo. (Fotografías: Art Graphique et Patrimoine)

con la sala pequeña-, alberga un proyector digital $2 \mathrm{~K}$ y un proyector de $35 \mathrm{~mm}$.

La sala pequeña situada también en el sótano, que cuenta con 74 plazas -71 sillas y tres sitios reservados para personas en silla de ruedas- ha sido diseñada con un estilo club con una bóveda en asa de cesta con un revestimiento microporoso, muros en terciopelo color rojo profundo organizados rítmicamente por pilastras en madera oscura, y sillas en cuero gris. Esta sala dispone de una pantalla fija de 4.80 metros de largo, y esta iluminada con un conjunto de rampas de diodos que resaltan el diseño de las pilastras y de los arcos en madera del decorado. El proyector asignado para esta sala es un proyector digital $2 \mathrm{~K}$ instalado en la cabina de proyección compartida con la sala mediana.

En la tercera planta, a la altura del pórtico, el foyer/sala de exposiciones ha recuperado el volumen original correspondiente al antiguo puesto
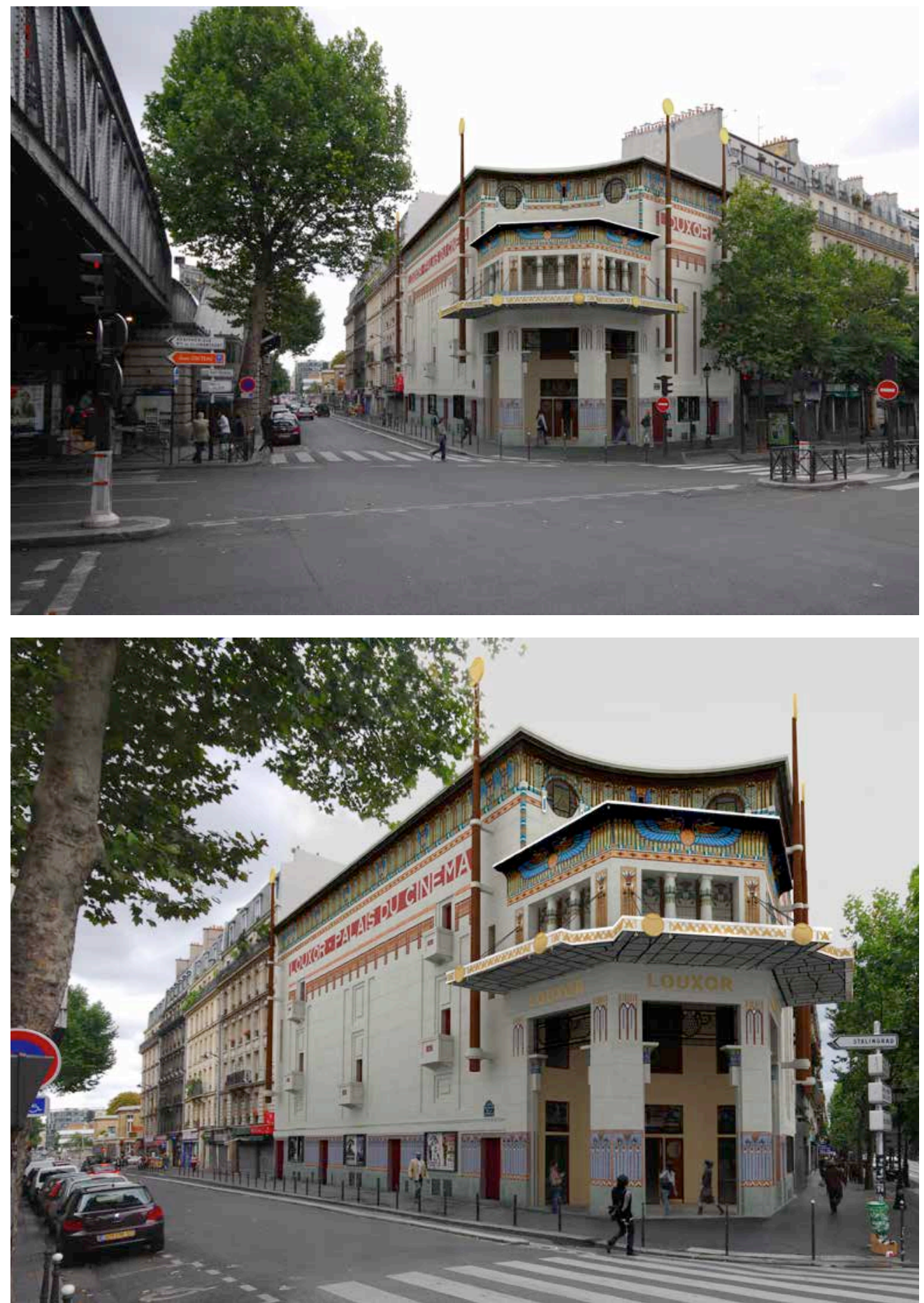


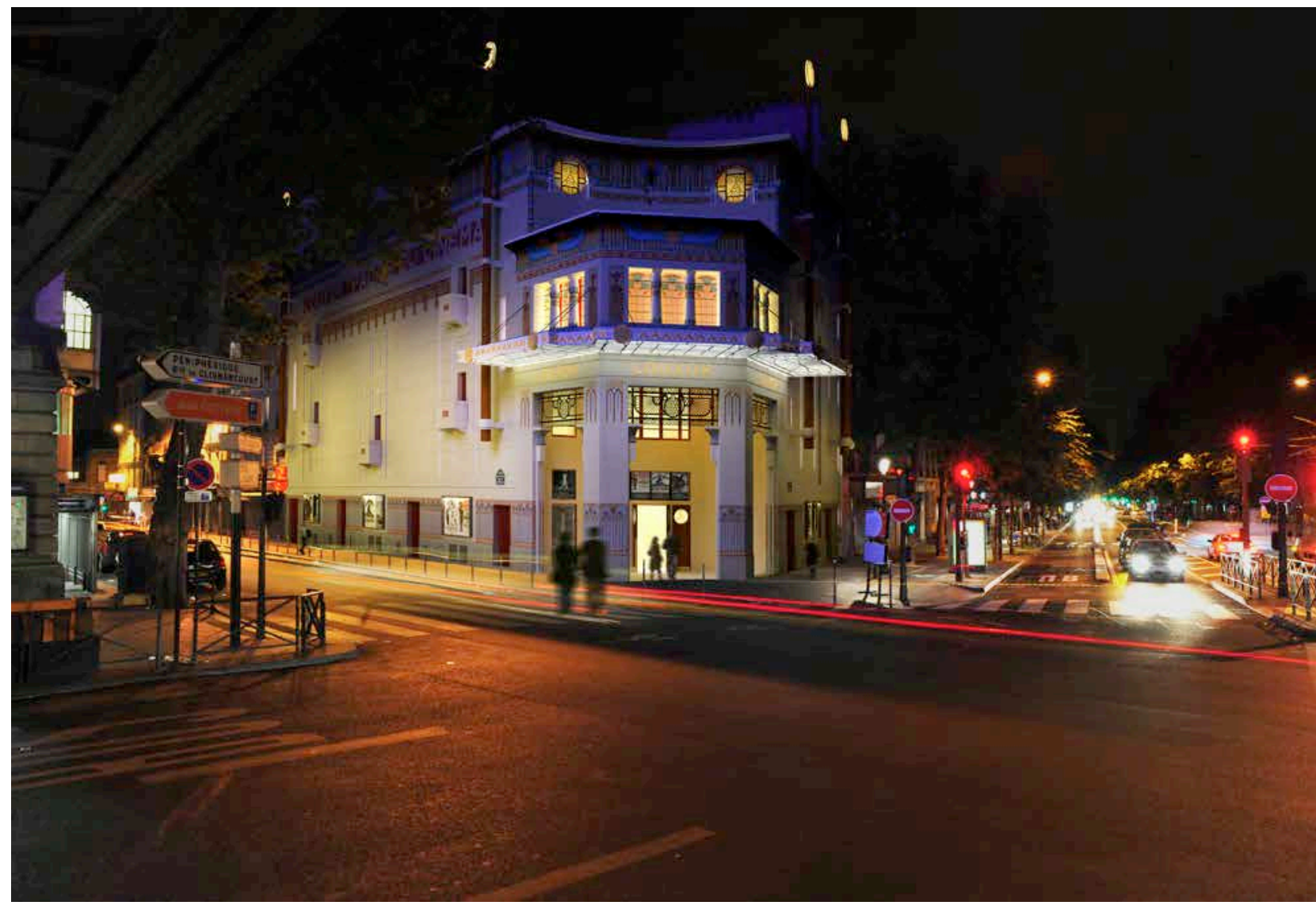

de bebidas que en 1921 recibía a los visitantes el Louxor, y que había sido transformado y compartimentado para albergar oficinas. En este espacio, los vitrales de estilo Art déco egiptizante crean una extraordinaria atmósfera luminosa.

El último espacio accesible al público es el bar, implantado en el cuarto piso -y contiguo al segundo balcón de la sala-, el cual goza de una terraza exterior ubicada sobre el foyer y el pórtico, con una agradable vista hacia Montmartre y la basílica del Sacré-Cœur.

Para acceder a las oficinas del Louxor, situadas en el quinto piso -sobre el bar- se dispuso un tramo adicional que prolonga la escalera histórica. Los espacios dedicados a las oficinas se abren hacia una terraza privada que bordea el edículo técnico que corona la gran sala. Una escalera metálica exterior que da sobre el pequeño patio interior permite conectar los espacios técnicos situados en la zona de la terraza con aquellos del sótano, totalmente independientes de las circulaciones públicas.

Al finalizar la obra, cuyos últimos trabajos tanto interiores como exteriores fueron realizados en marzo de 2013, los habitantes del barrio, así como los parisinos, cinéfilos y apasionados de la arquitectura y el patrimonio recibieron un cinema Louxor que había recuperado su antiguo esplendor, aunque modernizado y ampliado gracias a las dos salas creadas en el subsuelo. En algo menos de cinco años y medio después del primer contacto de nuestro equipo con el Louxor, la aventura llegaba a su fin, durante la primavera de 2013, cumpliendo con el calendario establecido y deseando que el renacimiento de este magnífico edificio parisino dedicado a la exhibición cinematográfica permitiera al público redescubrir el placer de frecuentar esta "sala obscura”, no sólo por la calidad de la programación ofrecida, sino además por las calidades espaciales y arquitectónicas puestas en valor y mejoradas con motivo del proyecto de rehabilitación.
Figura 46.

Vista nocturna del Louxor, días después de su reapertura en 2013, tras la rehabilitación descrita en el presente artículo. (Fotografías: Art Graphique et Patrimoine) 